Review Article

\title{
C-Terminal Binding Protein: A Molecular Link between Metabolic Imbalance and Epigenetic Regulation in Breast Cancer
}

\author{
Jung S. Byun and Kevin Gardner \\ Genetics Branch, Centers for Cancer Research, National Cancer Institute, 41 Library Drive, Bethesda, MD 20886, USA \\ Correspondence should be addressed to Kevin Gardner; gardnerk@mail.nih.gov
}

Received 4 December 2012; Revised 14 April 2013; Accepted 15 April 2013

Academic Editor: Claudia Cerella

Copyright (C) 2013 J. S. Byun and K. Gardner. This is an open access article distributed under the Creative Commons Attribution License, which permits unrestricted use, distribution, and reproduction in any medium, provided the original work is properly cited.

\begin{abstract}
The prevalence of obesity has given rise to significant global concerns as numerous population-based studies demonstrate an incontrovertible association between obesity and breast cancer. Mechanisms proposed to account for this linkage include exaggerated levels of carbohydrate substrates, elevated levels of circulating mitogenic hormones, and inflammatory cytokines that impinge on epithelial programming in many tissues. Moreover, recently many scientists have rediscovered the observation, first described by Otto Warburg nearly a century ago, that most cancer cells undergo a dramatic metabolic shift in energy utilization and expenditure that fuels and supports the cellular expansion associated with malignant proliferation. This shift in substrate oxidation comes at the cost of sharp changes in the levels of the high energy intermediate, nicotinamide adenine dinucleotide (NADH). In this review, we discuss a novel example of how shifts in the concentration and flux of substrates metabolized and generated during carbohydrate metabolism represent components of a signaling network that can influence epigenetic regulatory events in the nucleus. We refer to this regulatory process as "metabolic transduction" and describe how the C-terminal binding protein (CtBP) family of NADH-dependent nuclear regulators represents a primary example of how cellular metabolic status can influence epigenetic control of cellular function and fate.
\end{abstract}

\section{Introduction}

The first written description of breast cancer was recorded in 3000 B.C. as an inscription in the Smith Papyrus that pictured ulcerating lesions of the breast, a condition for which there was no cure [1]. Though, as early as Hippocrates (460$375 \mathrm{BC}$ ), the general belief was that cancer initiated from natural causes, a fuller understanding of cancer did not emerge until the late nineteenth century where the development of higher resolution microscopy made the visualization of cells and tissue possible [2]. This event marked the birth of modern pathology and revealed that there are striking differences in the appearance of cancer cells when compared to the surrounding normal tissue. This difference or "otherness" of malignancy made it clear that cancer develops from a change or transformation of normal tissue, a difference that modern molecular biology reveals to be rooted in genomic "changes" or mutation to cellular DNA sequence [3]. It is now widely recognized that mammalian cells are constantly exposed to genotoxic stress from both endogenous and exogenous sources that threaten to change or mutate the human genome and thereby increase the risk of cancer. To address this threat, mammalian cells and tissues have evolved numerous mechanisms and pathways to identify and repair damage to the human genome [4]. These DNA repair pathways and the manner in which cells and tissues provide surveillance to identify and remove cells that have irretrievably lost their genomic fidelity constitute what is known as the DNA damage response (DDR) $[3,4]$, which is now recognized as a major criteria through which clinicopathological assessment and classification of breast cancer are defined [5-8].

\section{The Molecular Stratification of Breast Cancer}

A significant development in the clinicopathological assessment of breast cancer has been the recognition that breast 
cancer is a heterogeneous disease that can be stratified into relatively distinct entities or subtypes based on specific molecular parameters $[6,9,10]$. At least 5 different classes or "subtypes" are described, including luminal A, luminal B, human epidermal growth factor 2 (HER2) positive, basallike, and claudin low [10]. Each of these subtypes has been shown to resemble or reflect distinct stages of mammary differentiation where the claudin low and basal-like represent the more primitive, receptor deficient, "triple negative" (lacking estrogen, progesterone, and HER2 receptors) spectrum of differentiation [11]. Most notably, a similar functional stratification exists with respect to DNA repair, where the less differentiated subtypes exhibit the greatest deficiencies in genome stability [5]. Since tumors with higher levels of genome instability typically show more aggressive behavior, it is clear that this stratification of breast cancer phenotypes and its functional correlation with DNA repair capacity have significant prognostic importance that will guide therapeutic strategies $[6,7,12,13]$. These relationships are well demonstrated by the observation that the gene products of the early onset breast cancer genes BRCA1 $[13,14]$ and BRCA2 [15], whose germline loss or mutation confers a near $80 \%$ risk of developing breast cancer, are themselves DNA repair proteins [16]. Moreover, patients with germline depletion of BRCA1 give rise to tumors of the more primitive, triple negative, basal-like, and claudin-low subtypes $[17,18]$. Similarly, sporadic tumors that show deficiencies in BRCA1 tend to be of the basal-like or claudin-low subtype, and estimates indicate that as many as $40 \%$ of nonhereditary or sporadic breast cancers show decreased expression of BRCA1 [19].

\section{Obesity, Diabetes, and the Risk of Breast Cancer}

It is estimated that obesity in United States accounts for nearly $15 \%-20 \%$ of cancer deaths $[20,21]$. Cancer death rates from women who are obese are from $50 \%$ to $60 \%$ higher than women who are of normal weight. Breast cancer rates in postmenopausal women increase $30 \%-50 \%$ with obesity and are associated with more aggressive disease. In fact, very obese women with a body mass index (BMI) greater than $40.0 \mathrm{~kg} / \mathrm{m}^{2}$ have a three times higher risk of death from disease compared to their much leaner $\left(B M I<20.5 \mathrm{~kg} / \mathrm{m}^{2}\right)$ counterparts [22]. Finally, as might be predicted, patients who are both obese and have germline BRCA1/2 mutations show significantly increased risk over either condition alone [23].

The relationship between obesity and breast cancer is complex. Most studies have focused on the abnormally elevated levels of circulating mitogenic hormones and inflammatory cytokines $[22,24,25]$. The rise in adipocyte size due to calorie excess causes increased release of free fatty acids and enhanced secretion of peptide hormones such as leptin, resistin, and tumor necrosis factor alpha ( $\mathrm{TNF} \alpha)$ and reduced release of adiponectin. Adipose cells also express significant levels of steroid hormone metabolizing enzymes. The high levels of TNF $\alpha$ and reduced level of adiponectin give rise to insulin resistance and type II diabetes [24, 25].
The elevated insulin levels result in increased production of insulin-like growth factor one (IGF-1), both of which promote cellular proliferation. Increased levels of steroid hormone metabolizing enzymes like aromatase in adipose cells convert circulating androgen precursor to estrogens. This rise in free circulating estrogen is further exacerbated by the reduced synthesis of the sex-hormone binding globulin (SHBG) due to the obesity-associated hyperinsulinemia [2426].

\section{The Molecular Cost of Metabolic Imbalance}

To define the link between obesity and cancer we must begin by understanding the molecular impact or "cost" of metabolic imbalance. Conditions of excess calories or "overnutrition" have profound effects on cellular metabolism [26]. Oxidation of free fatty acids, glucose, and other carbon intermediates by beta-oxidation, glycolysis, and the tricarboxylic acid cycle transfers electrons primarily to nicotinamide adenine dinucleotide $(\mathrm{NAD}+)$ to produce $\mathrm{NADH}$. The NADH produced in this fashion normally has several different fates including its oxidation in the presence of molecular oxygen via the mitochondrial electron transport chain to produce $\mathrm{H}_{2} \mathrm{O}$ and ATP. One well-understood consequence of the elevated NADH levels due to nutrient excess is the increased generation of reactive oxygen species (ROS) like superoxide $\left(\mathrm{O}_{2}{ }^{-}\right)$as a consequence of incomplete mitochondrial electron transfer during respiration $[27,28]$. The ROS, thus generated, contributes significantly to the risk of malignant transformation by causing DNA damage.

\section{NAD+/NADH and Cancer Metabolism}

The NAD+/NADH redox imbalance of nutrient excess and obesity is reminiscent of the metabolic imbalance associated with the malignant proliferation of cancer, first described by Otto Warburg in 1927 [26, 103-111]. In his work, Warburg noted that cancer cells demonstrated high levels of glucose consumption and lactic acid production even though there was significant oxygen to sustain the respiratory production of energy by the oxidation of NADH via oxidative phosphorylation. The net result is an elevation in the steady state levels of cellular NADH. This shift in energetic carbon flux is referred to as the Warburg Effect and has been the focus of extensive investigation as a potential vulnerability of cancer metabolism ("cancer's sweet tooth") that may be exploited for chemotherapeutic benefit $[106,107,109,111]$.

In addition to threats to genome integrity from elevated ROS, the shifts in the redox status and availability of $\mathrm{NAD}+$, due to either calorie excess or the Warburg Effect, have profound influence on certain specialized classes of mammalian proteins that directly utilize oxidized or reduced $\mathrm{NAD}+$ as cofactors, ligands, or substrates. Some of these factors have widespread impact on genome integrity by controlling the DNA damage response and include the Sirtuin family of Class III histone deacetylases [112, 113], the PARP family of poly ADP ribosyl-transferases [114-116], and the C-terminal binding protein $(\mathrm{CtBP})$ class of transcriptional 
repressors [117-120]. The relative $K_{M}$ of the Sirtuin and PARP family are in the 50-200 micromolar range [121]. Since the levels of free cytoplasmic NAD+ are in the range of 500800 micromolar, both the Sirtuin and PARP families are functioning at saturation. In contrast, the free cytoplasmic concentration of NADH is 1 micromolar, while the CtBP binding protein (CtBP) class of transcriptional repressors has binding affinity in the 100 nanomolar range [122]. Therefore, $\mathrm{CtBP}$ is likely to function as a true sensor of cellular metabolic status by sensing acute and chronic changes in cytoplasmic and nuclear levels of NADH.

This review will summarize the role of CtBP in the maintenance of genomic homeostasis and describe how its activity links cellular metabolic status with genome stability and epithelial reprogramming in breast cancer and how this linkage has broader implications for other epithelial cancers.

\section{C-Terminal Binding Protein Structure and Function}

$\mathrm{CtBP}$ is expressed from two genes, $C t B P 1$ and $C t B P 2$. Both of these genes give rise to many different isoforms, some displaying distinct functions. There are essentially four major CtBP isoforms: $C t B P 1-L$, a shorter isoform of $C t B P 1$ (CtBP1-S) referred to as $C t B P 3 / B A R S$, CtBP2 (including a $C t B P 2-L$ and shorter splice isoform CtBP2-S), and RIBEYE, a variant that contains a large $\mathrm{N}$-terminal domain and is transcribed from an alternate $C t B P 2$ promoter [119]. CtBP was first identified as a phosphoprotein that interacted with the C-terminal protein sequences encoded in exon 2 of the oncogenic adenovirus 2/5 E1A protein [123]. The CtBP protein was later found to function as a transcriptional corepressor when targeted to gene promoters through the C-terminal sequences of E1A [124]. This binding was mediated by a highly conserved 56 amino acids binding motif (PXDLSK) that adopted the conformation of a series of beta turns in solution [125]. The PXDLS binding motif was later found in a variety of transcriptional repressors across different species, including drosophila transcriptional regulators that play broad roles in tissue morphogenesis, like zfh-1, hairy, knirps, giant, kruppel and snail and its mammalian homologues snail, and ZEB1/2 $[29-32,126]$. A search for other proteins that interact with $\mathrm{CtBP}$ led to the identification of C-terminal binding protein interacting protein (CtIP) [127], a protein that was later implicated in having a significant role in maintaining genome stability through its interaction with the early onset breast cancer gene, BRCA1 [35], indicating that CtBP could bind to a diverse array of factors with distinct and overlapping molecular functions. This link was later expanded when it was found that Rb pocket binding LXCXE motif within CtIP enabled it to form higher order complexes with CtBP and $\mathrm{Rb}$ family members via a separate domain containing the common PXDLS motif indicating that CtIP/CtBP complexes represent a corepressor assembly that could recruit tumor suppressors like $\mathrm{Rb}$ in the context of histone deacetylase activity. Subsequently, CtBP began to show up in a variety of other protein interaction screens as binding partners for several different transcriptional regulators that control diverse cellular programs including Net (ELK4), a member of the ternary complex family involved in regulation of Fos and other immediate early gene expressions through the serum response element, and the transcriptional repressor KLF8 (ZNF741) [36, 37].

\section{Early Clues of Role for CtBP in Development}

CtBP is well conserved, and forms of CtBP are expressed from men to flies, worms, and plants [118, 128, 129]. Consistent with its role in tissue morphogenesis, first demonstrated in drosophila, several studies have identified a role for CtBP in driving mammalian epithelial programming where the cellular adhesion molecule E-cadherin is a major target of repression through the recruitment of CtBP/ZEB complexes to multiple E-box transcription factor binding sites (TFBS) in the E-cadherin (CHDI) promoter [130]. This study also shows that $\mathrm{CtBP}$ inhibits cell anoikis, suggesting a prominent role for CtBP in promoting the early stages of epithelialto-mesenchymal transition [130, 131]. Other lines of evidence are beginning to suggest significant roles for CtBP in epithelial reprogramming. For instance, gene expression studies in CtBP depleted cells reveal that multiple epithelial and proapoptotic gene pathways are regulated by CtBP [38]. Subsequently, several other genes have been found to be transcriptionally regulated by $\mathrm{CtBP}$, including the telomerase protein and RNA components, TERT and hTERC [132], the notch target gene Heyl [74], and the brain-derived neurotrophic factor $(B D N F)$ promoter through binding the REST transcription factor [133]. Transforming growth factor beta (TGF- $\beta$ ) plays a ubiquitous and multipotent role in regulating tissue morphogenesis. Under certain conditions, its influence is antiproliferative; yet under others, it can promote tumor progression and invasion [134]. The CtBP interaction with the transcriptional regulator Evi-1 protein, known for inducing blocks to differentiation that promote leukemogenesis, is also known to inhibit signaling through TGF- $\beta$ by associating with Smad3 containing complexes and recruiting CtBP [39]. This interference with TGF- $\beta$ signaling is also facilitated through the interaction of CtBP with inhibitory Smad 6 [60]. Accordingly, Evi-1 induced transformation of Ratla fibroblast requires $\mathrm{CtBP}$, the first indication that $\mathrm{CtBP}$ plays a direct role in cellular transformation [135]. Similarly, overexpressed and $t(3 ; 21)$ chimeric fusions of Evi-1 also function through CtBP to block differentiation and promote leukemogenesis $[136,137]$. CtBP transgenic studies show that CtBP plays roles in a vast variety of developmental functions [138]. While CtBP2 deletions are an embryonic lethal (E10.5), mice with CtBP1 disruption are viable and fertile but die early $[118,138]$.

\section{CtBP and NADH}

It was not until nearly a decade after its first discovery that $\mathrm{CtBP}$ was found to be an NADH regulated dehydrogenase of the well-conserved D2 hydroxyacid dehydrogenase class that undergoes a conformational change in association with either NAD+ or NADH [139]. Moreover, it was found that 
residues associated with the active site are linked to the ability of the dimeric components to bind to the PXDLS peptide motif on its binding partners [139]. Like other D2 hydroxyacid dehydrogenases (e.g., GAPDH), CtBP was found to form higher order oligomers and increase its interaction with PXDLS containing protein domains in the presence of NADH and NAD+ [140]. Moreover, its interaction with PXDLS containing peptides slowed the catalytic activity [140]. Notably, the binding affinity of CtBP was over 100fold higher for NADH than NAD+ suggesting a substantial role for CtBP as a metabolic sensor of redox status [122, 141]. However, ablation of enzymatic activity by mutations at histidine-315 showed no effect on CtBP transcriptional regulation, suggesting that NADH/NAD+ binding, not the dehydrogenase activity of CtBP, was necessary for its repressor activity [38, 142]. Nonetheless, a developmental study in drosophila revealed distinct phenotypes for CtBP with impaired enzymatic activity; so, the identity and role of the true substrate for the CtBP dehydrogenase remain a mystery [143].

\section{CtBP and Regulation of the Epigenome}

Several reports demonstrate that CtBP forms complexes with a variety of epigenetic regulators or corepressor complexes that recruit epigenetic regulators. Initial studies show that CtBP interacts with consensus binding motifs on class II histone deacetylases (HDAC 4, 5, and 7) and the corepressor protein MEF2-interacting transcription repressor (MITR/HDAC9), a structural scaffold that associates with other HDACs, through amino terminal sequences [40]. The class I histone deacetylases (HDACs, 1, 2, and 3) are also found to associate with CtBP through various multicomponent complexes $[42,144]$. In multiple studies, these complexes were found also to contain several different types of epigenetic regulators, including histone methyltransferases G9a and EHMT1; the G9a and EHMT1 binding zinc finger protein, WIZ, that bridges interaction with CtBP; the histone demethylase LSD1; an actin-related component of the SWI/SNF complex, ArpN $\alpha$; CoRest (RCOR1), a corepressor protein that interacts with REST transcription factor; CDYL, a component of the polycomb regulatory complex 2 (PRC2) that bridges interaction between repressive Histone H3K27Me3 modifications and the EZH2 histone H3K27 methyltransferase; and a component of the polycomb regulatory complex I (PRC1), CBX4 $[42-44,46]$. Since both G9a and CBX4 interact with DNA methyl-transferases [145-148], it is likely that some CtBP complexes will also contain DNA methyl-transferases. Recent findings indicate that the histone acetyl-transferase, p300, also forms complexes with CtBP. In the CtBP:p300 complex, CtBP interaction with the p300 bromodomain represses p300 HAT activity [45]. The BCL6 corepressor BCOR-L1 associates with CtBP in combination with class II HDACs (HDAC 4, 5, and 7) to repress target genes like E-cadherin [47]. The estrogen receptor corepressor, Rip140, forms a complex with CtBP to participate in control of hormone regulated genes [48]. Transcriptional repression through GATA2 and GATA3 is mediated by combined association of the corepressor, friend of GATA (FOG) with CtBP to block adipogenesis [49]. Another pathway through which CtBP controls adipocyte growth and differentiation is through the transcription factor PRDM16 that recruits CtBP to shut down genes that promote white adipose cell growth and differentiation and eventually exchanges CtBP factors for PGC- $1 \alpha$ and PPAR $\gamma$ to drive the expression of brown fat genes [50]. Finally, it has been shown that the p53 gene product and regulator hmd 2 can act as a corepressor at p53 regulated genes to recruit CtBP to mediate transcriptional repression [51].

Other DNA binding transcription factors regulated by $\mathrm{CtBP}$ include hypermethylated in cancer (HICl), which forms a complex with CtBP that regulates SIRT expression; ZNF36, which is involved in the regulation of estrogen controlled genes; BCL6, which binds directly to CtBP to autoregulate its own transcription; the corepressor BCL3 whose association with DNA bound NF-kappa B dimers requires CtBP for transcriptional repression; Ikaros, a transcription factor necessary for lymphoid development, whose repressive activity requires a direct interaction with $\mathrm{CtBP}$ through an N-terminal PXDLS motifs and an interaction between $\mathrm{CtBP}$ and Sin3A; the TCF- 4 of Wnt signaling whose physiological repression of $\mathrm{CtBP}$ target genes is lost in cancers that are deficient in mismatch repair and express TCF-4 isoforms incapable of binding CtBP [53-56, 58, 149-151].

\section{Posttranslational Regulation of CtBP}

CtBP protein undergoes dynamic posttranslational regulation (see Table 2). The changes influence either the stability or the subcellular localization of CtBP. CtBP2 and CtBP1 readily hetero- and homodimerize; however, only CtBP2 has a nuclear localization signal that allows it to translocate to the nucleus. Thus, CtBP1 must either enter the nucleus as a heterodimer with $\mathrm{CtBP} 2$ or through the formation of a complex with BKLF (KLF3) or other factors [57]. This mode of translocation is heavily dependent on CtBP1 dimerization so decreases in dimerization; through decreased availability of NADH can result in retention of CtBP1 in the cytoplasm [57]. The nuclear splicing factor Pnn/Drs has recently been found to be recruited to gene promoters by CtBP to influence splicing [152]. This interacting Pnn/CtBP complex also plays a role in sequestering $\mathrm{CtBP}$ in nuclear speckles to relieve transcriptional repression of CtBP-targeted genes [59]. Finally, the subcellular localization of CtBP is dynamically controlled by posttranslational modifications. Sumoylation of CtBP1 at lysine K428 results in increased nuclear retention [98]. Similarly, acetylation of CtBP2 by p300/CBP on lysine residues $\mathrm{K} 6, \mathrm{~K} 8$, and especially K10 results in nuclear retention [153]. Interestingly, sumoylation of CtBP1 was inhibited in the cytoplasm by the PDZ protein nNOS resulting in greater cytoplasmic retention $[78,98]$. The total levels of CtBP1 sumoylation appear low, and so the relative contribution of this modification to $\mathrm{CtBP}$ regulation remains unclear; however, CBX4 (see earlier), PIAS1, PIASx $\alpha$, and PIASx $\beta$ have been shown to be the likely E3 ligases involved [154156]. The role of CBX4 in the regulation of CtBP1 remains complicated as CBX4 promotes complex formation between 
CtBP1 and ATK1, where ATK1 dependent phosphorylation of CtBP1 results in decreased dimerization and increased ubiquitination with subsequent proteasomal degradation [96]. Interestingly, CtBP1 is also phosphorylated on Ser-158 by AMP Kinase (AMPK) which results in decreased repressive function, suggesting a novel mechanism through which CtBP activities are controlled by nutrient stress [93].

Two previous reports have shown that the adenomatous polyposis coligene (APC) interacts with $\mathrm{CtBP}$ and regulates its degradation through a proteasomal pathway $[61-63,85]$. In fact, degradation or loss of CtBP was proposed as a necessary step in the evolution of colonic adenomas in a zebrafish model [63]. Another tumor suppressor gene that is associated with CtBP degradation is alternative read frame tumor suppressor gene ARF whose association with CtBP leads to its degradation [157]. Phosphorylation of CtBP on Ser-422 by homeodomain interaction protein kinase 2 (HIPK2) leads to its ubiquitination and proteasomal degradation in response to UV irradiation [65]. Similarly, c-jun NH2 terminal kinase 1 (JNK1) also phosphorylates CtBP on Ser-422 [66] suggesting that the induction of stress pathways may be a common mechanism to reduce the level of CtBP posttranslationally. Phosphorylation of CtBP on serine 158 by the p21 activated kinase PAK1 triggers relocalization to the cytoplasm [97]. Recent studies indicate that phosphorylation of CtBP on T144 by cyclic-AMP dependent kinase (PKA) leads to increased dimerization [92]. The interaction of CtBP with X-linked inhibitor of Apoptosis (XIAP) also leads to its ubiquitination and degradation. Though the mechanism of degradation has yet to be fully described, the removal of phosphorylated $\mathrm{CtBP}$ from promoter bound locations is thought to require the action of the transducin beta family of chaperone-like molecules, TBL1 [67]. Finally, very recently the C-terminus of Hsc70-interacting protein was found to interact with CtBP2 leading to its ubiquitination and subsequent degradation in the proteasome [95].

\section{Moonlighting Functions of CtBP in the Cytoplasm}

The fission and fusion of biological membranes during intracellular trafficking of membrane bound vesicles and structures support broad programs of endocytosis and exocytosis as essential cellular functions. Both forms of CtBP1 (CtBP1-L and the CtBP3/BARS/CtBP1-S) have cytoplasmic functions that remain to be clearly defined but appear to be linked to Golgi membrane fission and homeostasis $[119,158]$. $\mathrm{CtBP} 3 / \mathrm{BARS}$ is reported to have an essential role in regulating membrane fission in the Golgi tubular network and has also been implicated in mitotic partitioning of the Golgi apparatus $[159,160]$. Though the mechanism and putative enzymatic activity exerted by CtBP in this processes remain unresolved $[161,162]$, there is general agreement for a central role of $\mathrm{CtBP}$ in the formation of vesicular and tubular membrane carriers that ferry membrane bound components to different intracellular compartments [163]. How this function may impact on the nuclear function of CtBP and how such activity influences the role of CtBP in development and oncogenesis remain unclear. Some reports suggest that loss of CtBP3/BARS is associated with decreased surface expression of the FAS/CD95 [164]; therefore, this mechanism may have a role in cellular survival strategies. However, given the known role of CtBP in influencing cellular reprograming and antagonizing the epithelial phenotype [118], it is tempting to speculate that this property of CtBP could have a role in defining epithelial polarity [165-167]. The partitioning of the Golgi during mitosis may also have a significant role in promoting formation and orientation of the mitotic spindle and thus could influence the asymmetric division necessary for the formation of stratified epithelia and the maintenance of pluripotent stem cell pools $[168,169]$. Similar membrane trafficking promoted by CtBP3/BARS may have a role in maintaining the basolateral and apical polarity of epithelial cells during tissue morphogenesis, regeneration, and wound healing. All of these events are disrupted and deregulated in cancer. Finally, it is tempting to speculate that secretory tissues that must undergo cyclic proliferation and involution or repair (e.g., breast, endometrium, and colon) may be particularly dependent on both the nuclear and cytoplasmic functions of CtBP.

\section{CtBP and Oncogenesis}

Since its discovery in 1993, many studies provide evidence that CtBP plays an expanded role in the evolution and progression of cancer controlling gene expression through a variety of transcriptional regulators and gene networks (Table 1). Many of these networks are associated with malignant behavior in a variety of cell types. CtBP recruitment and transcriptional targeting of multiple genes important in hematopoietic differentiation, including Evi-1, BCL3, BCL6, GATA1, GATA2/3, FOG1, and Ikaros strongly implicate prominent roles for CtBP in the incidence and progression of erythroid, lymphoid, and myeloid malignancies $[39,49,54,56,58,136$, 170, 171]. Similarly, the interaction of CtBP with a variety of developmentally regulated genes that control various processes in tissue development, like EMT, strongly implicates a significant role for CtBP in the incidence, growth, and progression of epithelial cancers $[38,130,172]$. As mentioned previously, the control of CtBP protein levels by APC was one of the earliest indications of a link between CtBP and epithelial cancers $[62,85,173]$. In fact, the earlier studies that linked CtBP function to EMT were carried out in lung and colonic cell lines and tissues $[174,175]$. These have been augmented by studies with patient tissue showing correlation between $\mathrm{CtBP}$ expression and malignancy. Nadauld et al. showed that CtBP could be linked to impaired differentiation in colon cancer because it decreased the production of retinoic acid through repression of retinol dehydrogenase [62]. In this study, the investigators were able to show that, in colonic biopsies from patients with familial adenomatous polyposis (FAP) (germline deficiencies in APC, which induces CtBP degradation), adenomas showed elevated levels of CtBP1 that was correlated with reduced levels of retinol dehydrogenase expression [62]. Deng et al. found that CtBP1 expression was elevated in a large percentage patient melanomas [176]. 
TABLE 1: CtBP interacting protein complexes.

\begin{tabular}{|c|c|c|}
\hline Factor & Function & Ref \\
\hline Zfh-1 & Transcription repression & [29] \\
\hline Hairy & Transcription repression & {$[30]$} \\
\hline Knirps & Transcription repression & {$[31]$} \\
\hline Giant & Transcription repression & {$[32]$} \\
\hline Kruppel & Transcription repression & {$[32]$} \\
\hline Snail & Transcription repression & {$[32]$} \\
\hline ZEB1/2 & Transcription repression & {$[33]$} \\
\hline CtIP & Genome stability & {$[34]$} \\
\hline BRCA1 & Transcription repression & {$[35]$} \\
\hline NET (ELK4) & Transcription repression & {$[36]$} \\
\hline KLF8 (ZNF741) & Transcription repression & {$[37,38]$} \\
\hline Evi-1 & $\begin{array}{l}\text { Inducing blocks to } \\
\text { differentiation }\end{array}$ & {$[39]$} \\
\hline HDAC $4,5,7$ & Histone deacetylation & {$[40]$} \\
\hline $\operatorname{HDAC} 1,2,3$ & Histone deacetylation & {$[41,42]$} \\
\hline G9a & Histone methyltransferase & {$[42]$} \\
\hline EHMT1 & Histone methyltransferase & {$[43]$} \\
\hline WIZ & Transcription repression & {$[44]$} \\
\hline Lsd1 & Histone demethylase & {$[42]$} \\
\hline $\operatorname{ArpN} \alpha$ & Transcription repression & {$[45]$} \\
\hline CoRest (RCOR1) & Transcription repression & {$[42]$} \\
\hline CDYL & Transcription repression & {$[46]$} \\
\hline $\mathrm{CBX} 4$ & Transcription repression & {$[46]$} \\
\hline P300 & HAT inhibition & {$[47]$} \\
\hline BCOR-L1 & Transcription repression & {$[48]$} \\
\hline RIP140 & Hormone regulation & [49] \\
\hline FOG & Transcription repression & {$[50]$} \\
\hline PRDM16 & Transcription repression & {$[51]$} \\
\hline Hmd2 & Transcription repression & {$[52]$} \\
\hline HIC1 & Regulate SIRT expression & {$[53,54]$} \\
\hline ZNF366 & $\begin{array}{l}\text { Estrogen control gene } \\
\text { regulation }\end{array}$ & {$[55]$} \\
\hline BCL3 & Transcription repression & {$[56]$} \\
\hline BCL6 & $\begin{array}{l}\text { Autoregulation of } \\
\text { transcription }\end{array}$ & [56] \\
\hline Ikaros & Transcription repression & {$[57]$} \\
\hline $\operatorname{Sin} 3 \mathrm{~A}$ & Transcription repression & {$[57]$} \\
\hline TCF4 & Transcription repression & {$[58]$} \\
\hline BKLF (KLF3) & $\begin{array}{l}\text { Stability of subcellular } \\
\text { localization }\end{array}$ & {$[59]$} \\
\hline Pnn & Transcription Repression & {$[60]$} \\
\hline APC & Degradation & {$[61-64]$} \\
\hline ARF & Degradation & [65] \\
\hline HIPK2 & $\begin{array}{l}\text { Ubiquitination, } \\
\text { proteasomal degradation }\end{array}$ & {$[66]$} \\
\hline JNK1 & Phosphorylation & {$[67]$} \\
\hline TBL1 & Dephosphorylation & {$[67]$} \\
\hline $\mathrm{CDK} 7 / \mathrm{CCNH}$ & Post-translational stability & {$[68]$} \\
\hline
\end{tabular}

TABle 1: Continued.

\begin{tabular}{|c|c|c|}
\hline Factor & Function & Ref \\
\hline Huntingtin & Unknown & [69] \\
\hline Glis2 & Transcriptional repression & {$[70]$} \\
\hline PLD1 & $\begin{array}{l}\text { Activation of } \\
\text { macropinocytosis }\end{array}$ & [71] \\
\hline Smad6 & Transcriptional repression & {$[60]$} \\
\hline Ataxin & CtBP antagonism & \\
\hline PARP1 & Corepressor complex & {$[72]$} \\
\hline Sox6 & Transcriptional repression & {$[73]$} \\
\hline Spen & Transcriptional repression & {$[74]$} \\
\hline \multirow{2}{*}{ BCoRL1 } & BCL6 transcriptional & [47] \\
\hline & Co-repression & \\
\hline $\begin{array}{l}\text { Eos (IKaros family } \\
\text { member) }\end{array}$ & Transcriptional repression & {$[75]$} \\
\hline $\begin{array}{l}\text { Acetylcholinesterase-S } \\
\text { (AChE-S) }\end{array}$ & $\begin{array}{l}\text { Antagonize CtBP } \\
\text { transcriptional repression }\end{array}$ & [76] \\
\hline SatB1 & Co-repressor complex & [77] \\
\hline nNos & Cytoplasmic localization & [78] \\
\hline Tel/EVT6 & $\begin{array}{l}\text { Control of endothelial } \\
\text { sprouting }\end{array}$ & [79] \\
\hline ER-beta & $\begin{array}{l}\text { Suppression of } \\
\text { inflammatory response in } \\
\text { CNS microglia and } \\
\text { astrocytes }\end{array}$ & [80] \\
\hline KLF12 & Transcriptional repression & {$[81]$} \\
\hline MLL & Transcriptional repression & [82] \\
\hline HDGF & Transcriptional repression & [83] \\
\hline KCNIP3/KCHIP & $\begin{array}{l}\text { Calcium-dependent } \\
\text { Transcriptional repression }\end{array}$ & [84] \\
\hline MITR & Transcriptional repression & [40] \\
\hline
\end{tabular}

Increased expression of both CtBP1 and CtBP2 has been seen in tumors from patients with head and neck squamous cell cancers $[177,178]$. A very recent study reported an elevation of CtBP2 in ovarian cancer and suggested that CtBP2 expression could be used as a marker for patients that are more likely to respond to epigenetic therapy utilizing histone deacetylase inhibitors [179]. Another group at the University of Michigan recently reported that CtBP1 was overexpressed and mislocated in metastatic prostate cancer and suggested a prominent role for $\mathrm{CtBP} 1$ in the progression of prostate cancer [180]. Several recent studies provide strong evidence indicating that elevated CtBP expression and activity may play a significant role in human breast cancer $[172,181-$ 185]. In each study, increased CtBP expression was found in malignant as opposed to nontransformed patient samples. Yet, a systematic profiling of the network of genes controlled by CtBP in human breast cancer and the implication of that control in breast cancer evolution and outcome has been lacking. 
TABLE 2: CtBP regulators

\begin{tabular}{|c|c|c|}
\hline Protein & Mode of regulation & Ref. \\
\hline \multirow{2}{*}{ APC } & Protein degradation & {$[61-63,85]$} \\
\hline & Proteasome dependent & \\
\hline \multirow{2}{*}{ HIPK2 } & Phosphorylation-dependent & {$[86,87]$} \\
\hline & Protein degradation & \\
\hline \multirow{2}{*}{ TBL1 } & Protein degradation & [88] \\
\hline & Proteasome-dependent & \\
\hline \multirow{2}{*}{ Ink4a/Arf } & Protein degradation & {$[89,90]$} \\
\hline & Proteasome mediated & [64] \\
\hline BCL3 & Protein Stabilization & [91] \\
\hline PKA & CtBP dimerization & [92] \\
\hline AMPK1 & $\begin{array}{l}\text { Phosphorylation dependent } \\
\text { inactivation }\end{array}$ & [93] \\
\hline XIAP & Polyubiquitination degradation & [94] \\
\hline Stub1/CHIP & $\begin{array}{l}\text { CtBP2 polyubiquitination } \\
\text { degradation }\end{array}$ & [95] \\
\hline AKT1 & $\begin{array}{l}\text { Phosphorylation induced decreased } \\
\text { dimerization }\end{array}$ & {$[96]$} \\
\hline \multirow[t]{2}{*}{ JNK1 } & Phosphorylation dependent & [66] \\
\hline & Proteasomal degradation & \\
\hline \multirow{2}{*}{ PAK1 } & Phosphorylation dependent & [97] \\
\hline & Translocation to the cytoplasm & \\
\hline CBX4/UBC9 & $\begin{array}{l}\text { Sumoylation-dependent nuclear } \\
\text { retention }\end{array}$ & {$[98-101]$} \\
\hline p300 & $\begin{array}{l}\text { Acetylation increased nuclear } \\
\text { retention }\end{array}$ & [102] \\
\hline
\end{tabular}

\section{Genome-Wide Profiling of CtBP Interactions across the Breast Cancer Genome}

Beginning with the observation that CtBP could act as a metabolic sensor to control genome stability in breast cancer through the early onset gene BRCAl, one group at the National Cancer Institute has provided one of the first comprehensive genomic analyses of the interaction of CtBP with the human genome [185]. Using a combination of chromatin immunoprecipitation and deep sequencing (ChIPseq), this group identified more than 1800 gene promoters that were potential candidates for transcriptional regulation by CtBP [185]. Remarkably, many of the genes that were targets of CtBP repression fell into 3 major classes: those genes that influenced genome stability (e.g., BRCA1, BRIP1, RAD51C, ERCC5, PALB2, FANCD2, XRCC5, and FANCM); those genes that controlled epithelial differentiation and are therefore down regulated during EMT (e.g., CDH1, CST6, CLDN3, CLDN7, CLDN9, GRHL2, KRT18, and PARD6B); those genes that are routinely repressed to maintain stemcell like self-renewal and pluripotency (e.g., HES1, OVOL2, FOXA1, GATA3, DKK1, CEBPb, RARG, and OAZ3) [185] (see Figure 1). This was an important finding since these pathways represent significant hallmarks of cancer that play major roles in more aggressive forms of cancer through the promotion of uncontrolled growth, resistance to chemotherapy, and invasion and metastasis [186, 187]. As mentioned earlier, breast cancer subtypes stratify by morphology, molecular attributes, and prognosis along a hierarchy that reflects normal mammary epithelial development [188-190]. Tumors with high levels of phenotypic plasticity characterized by primitive, embryonic, or dedifferentiated mesenchymal features are usually of the basal-like and claudin-low subtypes. These tumors are typically estrogen receptor negative and the majority are also negative for the progesterone receptor and the human EGF receptor 2 (HER2) [189-191]. Such receptor negative tumors are often referred to as triple negative breast cancer (TNBC). These tumors also have the worst clinical outcomes with high mortality within the first five years after diagnosis [189-192]. Key molecular attributes of these tumors are increased genome instability, early invasion and metastasis, resistance to chemotherapy, and high expression of stem cell-like self-renewal pathways [189-194]. Strikingly, the CtBP target genes identified in this study could be readily used as a "signature" to predict poor clinical outcome based on metastasis free interval [185]. Moreover, using human breast cancer cell lines, the authors showed that disruption of CtBP, by either gene depletion or calorie restriction to lower endogenous NADH levels, increased DNA repair and diminished both the stem cell-like and invasive attributes of the cancer cells thus establishing a clear mechanistic link between CtBP, cellular metabolic status, and aggressive features of breast cancer. Finally, a screen of clinical samples from breast cancer patients revealed that those patients that had the highest expression of CtBP in their tumors had substantially shortened median breast cancer survival [185].

\section{Conclusion}

In this short review, we have described how, $\mathrm{NADH}$, a central product of carbohydrate metabolism can act as a secondary messenger to control the activity of multiple different epigenetic regulatory complexes in human cells and how these modes of regulation, when disrupted by metabolic imbalance, can increase the risk of cancer of the breast and other types. The linkage in metabolism and epigenetic modification provides a novel window through which one could assemble newer strategies for therapy with particular focus on the nexus between metabolism and epigenetic modifiers. In this regard, it is reasonable to conjecture that certain metabolic therapies could have the potential to show efficacy in combination with epigenetic modalities in the treatment of breast and other cancers. The heightened excitement raised about the reported efficacy of the antidiabetic drug, metformin, as both a chemopreventive and treatment strategy in breast cancer is just one example $[195,196]$. Other examples include the use of metabolic transducers like CtBP as a biomarker for efficacy in epigenetic therapy [179]. Since a direct effect of metformin is to increase AMPK activity, the finding that AMPK inhibits CtBP activity [93] certainly lends credence to such notion. Thus, new strategies to search for potential small molecules that may disrupt CtBP function could represent 


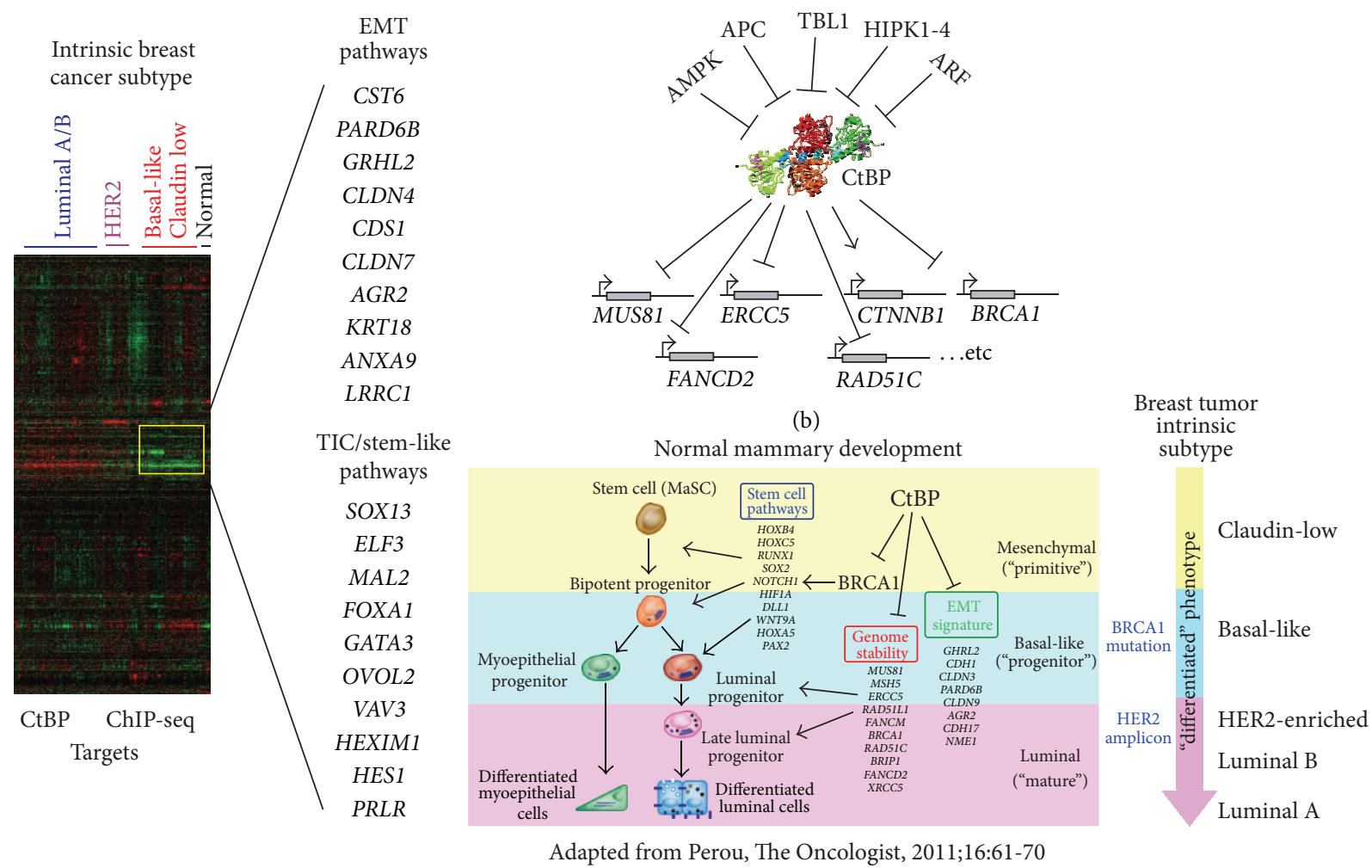

(a)

(c)

FIGURE 1: CtBP targets a network of interactions that control cellular reprogramming. (a) ChIP-Seq signature identifies multiple genes that are downregulated in breast cancer subtypes with primitive and mesenchymal features including the basal-like and claudin-low subtypes. (b) The CtBP targeted genes represent a network that exerts transcriptional control at the level of gene promoters and posttranslational stability of CtBP. (c) Representative genes targeted by CtBP influence cellular programming that correlate with primitive and more clinically aggressive intrinsic subtypes of breast cancer.

a novel form of epigenetic therapy where the target is genespecific recruitment of chromatin modifying enzymes rather than the wholesale nonspecific repression of a whole enzyme class.

While we specifically focus on CtBP, a pleiotropic regulatory complex controlling numerous epigenetic modifications, whose activities are "metabolically transduced" by NADH, there are clearly many other metabolic intermediates that influence epigenetic modifications and therefore provide a means through which aspects of metabolic status can be transduced to affect changes in gene expression through epigenetic regulation. Among them are the wide array of histone acetyl-transferases that utilize acetyl-CoA for producing epigenetic marks, the PARP family of proteins that modify chromatin by ADP-ribosylation, the Sirtuin family that consumes NAD+ during histone deacetylation, the Jumonji C family of histone methyl-transferases that utilize alpha-ketoglutarate, and the TET1/2 family of $5 \mathrm{mC}$ oxidases that also consume alpha-ketoglutarate to influence DNA methylation. The manner in which the activities of these epigenetic regulators are coordinated with each other to sculpt and shape the epigenome in response to cellular metabolism represents a new area of investigation that will have broad implication not only in cancer but in a wide variety of human diseases.

\section{References}

[1] S. I. Hajdu, "A note from history: landmarks in history of cancer, part 1," Cancer, vol. 117, no. 5, pp. 1097-1102, 2011.

[2] R. Virchow, "An address on the value of pathological experiments," British Medical Journal, vol. 2, no. 1075, pp. 198-203, 1881.

[3] S. P. Jackson and J. Bartek, "The DNA-damage response in human biology and disease," Nature, vol. 461, no. 7267, pp. 10711078, 2009.

[4] A. Ciccia and S. J. Elledge, "The DNA damage response: making it safe to play with knives," Molecular Cell, vol. 40, no. 2, pp. 179204, 2010.

[5] B. P. Schneider, E. P. Winer, W. D. Foulkes et al., "Triple-negative breast cancer: risk factors to potential targets," Clinical Cancer Research, vol. 14, no. 24, pp. 8010-8018, 2008.

[6] J. Peppercorn, C. M. Perou, and L. A. Carey, "Molecular subtypes in breast cancer evaluation and management: divide and conquer," Cancer Investigation, vol. 26, no. 1, pp. 1-10, 2008. 
[7] B. P. Rowe and P. M. Glazer, "Emergence of rationally designed therapeutic strategies for breast cancer targeting DNA repair mechanisms," Breast Cancer Research, vol. 12, no. 2, article 203, 2010.

[8] C. M. Perou, "Molecular stratification of triple-negative breast cancers," The Oncologist, vol. 16, supplement 1, pp. 61-70, 2011.

[9] C. M. Perou, "Molecular stratification of triple-negative breast cancers," The Oncologist, vol. 15, supplement 5, pp. 39-48, 2010.

[10] C. M. Perou, T. Sørile, M. B. Eisen et al., "Molecular portraits of human breast tumours," Nature, vol. 406, no. 6797, pp. 747-752, 2000.

[11] A. Prat and C. M. Perou, "Mammary development meets cancer genomics," Nature Medicine, vol. 15, no. 8, pp. 842-844, 2009.

[12] C. K. Anders, A. M. Deal, C. R. Miller et al., "The prognostic contribution of clinical breast cancer subtype, age, and race among patients with breast cancer brain metastases," Cancer, vol. 117, no. 8, pp. 1602-1611, 2011.

[13] J. M. Hall, M. K. Lee, B. Newman et al., "Linkage of early-onset familial breast cancer to chromosome 17q21," Science, vol. 250, no. 4988, pp. 1684-1689, 1990.

[14] Y. Miki, J. Swensen, D. Shattuck-Eidens et al., "A strong candidate for the breast and ovarian cancer susceptibility gene BRCA1," Science, vol. 266, no. 5182, pp. 66-71, 1994.

[15] R. Wooster, G. Bignell, J. Lancaster et al., "Identification of the breast cancer susceptibility gene BRCA2," Nature, vol. 378, pp. 789-792, 1995.

[16] D. Ford, D. F. Easton, M. Stratton et al., "Genetic heterogeneity and penetrance analysis of the BRCA1 and BRCA2 genes in breast cancer families. The Breast Cancer Linkage Consortium," The American Journal of Human Genetics, vol. 62, no. 3, pp. 676689, 1998.

[17] J. Palacios, E. Honrado, A. Osorio, O. Diez, C. Rivas, and J. Benítez, "Re: Germline BRCA1 mutations and a basal epithelial phenotype in breast cancer," Journal of the National Cancer Institute, vol. 96, no. 9, pp. 712-714, 2004.

[18] E. Honrado, A. Osorio, J. Palacios, and J. Benitez, "Pathology and gene expression of hereditary breast tumors associated with BRCA1, BRCA2 and CHEK2 gene mutations," Oncogene, vol. 25, no. 43, pp. 5837-5845, 2006.

[19] N. C. Turner, J. S. Reis-Filho, A. M. Russell et al., "BRCA1 dysfunction in sporadic basal-like breast cancer," Oncogene, vol. 26, no. 14, pp. 2126-2132, 2007.

[20] E. E. Calle, C. Rodriguez, K. Walker-Thurmond, and M. J. Thun, "Overweight, obesity, and mortality from cancer in a prospectively studied cohort of U.S. Adults," The New England Journal of Medicine, vol. 348, no. 17, pp. 1625-1638, 2003.

[21] E. E. Calle and M. J. Thun, "Obesity and cancer," Oncogene, vol. 23, no. 38, pp. 6365-6378, 2004.

[22] E. E. Calle and R. Kaaks, "Overweight, obesity and cancer: epidemiological evidence and proposed mechanisms," Nature Reviews Cancer, vol. 4, no. 8, pp. 579-591, 2004.

[23] J. Kotsopoulos, O. I. Olopado, P. Ghadirian et al., "Changes in body weight and the risk of breast cancer in BRCA1 and BRCA2 mutation carriers.," Breast Cancer Research, vol. 7, no. 5, pp. R833-R843, 2005.

[24] K. E. Wellen and G. S. Hotamisligil, "Inflammation, stress, and diabetes," The Journal of Clinical Investigation, vol. 115, no. 5, pp. 1111-1119, 2005.

[25] K. E. Wellen and G. S. Hotamisligil, "Obesity-induced inflammatory changes in adipose tissue," The Journal of Clinical Investigation, vol. 112, no. 12, pp. 1785-1788, 2003.
[26] K. E. Wellen and C. B. Thompson, "Cellular metabolic stress: considering how cells respond to nutrient excess," Molecular Cell, vol. 40, no. 2, pp. 323-332, 2010.

[27] J. F. Turrens, "Mitochondrial formation of reactive oxygen species," Journal of Physiology, vol. 552, no. 2, pp. 335-344, 2003.

[28] M. P. Murphy, "How mitochondria produce reactive oxygen species," Biochemical Journal, vol. 417, no. 1, pp. 1-13, 2009.

[29] A. A. Postigo and D. C. Dean, "Differential expression and function of members of the zfh-1 family of zinc finger/homeodomain repressors," Proceedings of the National Academy of Sciences of the United States of America, vol. 97, no. 12, pp. 6391-6396, 2000.

[30] G. Poortinga, M. Watanabe, and S. M. M. Parkhurst, "Drosophila CtBP: a Hairy-interacting protein required for embryonic segmentation and Hairy-mediated transcriptional repression," EMBO Journal, vol. 17, no. 7, pp. 2067-2078, 1998.

[31] Y. Nibu, H. Zhang, and M. Levine, "Interaction of short-range repressors with Drosophila CtBP in the embryo," Science, vol. 280, no. 5360, pp. 101-104, 1998.

[32] Y. Nibu and M. S. Levine, "CtBP-dependent activities of the short-range giant repressor in the Drosophila embryo," Proceedings of the National Academy of Sciences of the United States of America, vol. 98, no. 11, pp. 6204-6208, 2001.

[33] A. A. Postigo and D. C. Dean, "ZEB represses transcription through interaction with the corepressor CtBP," Proceedings of the National Academy of Sciences of the United States of America, vol. 96, no. 12, pp. 6683-6688, 1999.

[34] U. Schaeper, T. Subramanian, L. Lim, J. M. Boyd, and G. Chinnadurai, "Interaction between a cellular protein that binds to the C-terminal region of adenovirus E1A (CtBP) and a novel cellular protein is disrupted by E1A through a conserved PLDLS motif," The Journal of Biological Chemistry, vol. 273, no. 15, pp. 8549-8552, 1998.

[35] X. Yu, L. C. Wu, A. M. Bowcock, A. Aronheim, and R. Baer, "The C-terminal (BRCT) domains of BRCA1 interact in vive with CtIP, a protein implicated in the CtBP pathway of transcriptional repression," The Journal of Biological Chemistry, vol. 273, no. 39, pp. 25388-25392, 1998.

[36] P. Criqui-Filipe, C. Ducret, S. M. Maira, and B. Wasylyk, "Net, a negative Ras-switchable TCF, contains a second inhibition domain, the CID, that mediates repression through interactions with CtBP and de-acetylation," EMBO Journal, vol. 18, no. 12, pp. 3392-3403, 1999.

[37] J. van Vliet, J. Turner, and M. Crossley, "Human Kruppel-like factor 8: a CACCC-box binding protein that associates with CtBP and represses transcription," Nucleic Acids Research, vol. 28, no. 9, pp. 1955-1962, 2000.

[38] M. Grooteclaes, Q. Deveraux, J. Hildebrand, Q. Zhang, R. H. Goodman, and S. M. Frisch, "C-terminal-binding protein corepresses epithelial and proapoptotic gene expression programs," Proceedings of the National Academy of Sciences of the United States of America, vol. 100, no. 8, pp. 4568-4573, 2003.

[39] K. Izutsu, M. Kurokawa, Y. Imai, K. Maki, K. Mitani, and H. Hirai, "The corepressor CtBP interacts with Evi-1 to repress transforming growth factor $\beta$ signaling," Blood, vol. 97, no. 9, pp. 2815-2822, 2001.

[40] C. L. Zhang, T. A. McKinsey, J. R. Lu, and E. N. Olson, "Association of COOH-terminal-binding protein (CtBP) and MEF2-interacting transcription repressor (MITR) contributes to transcriptional repression of the MEF2 transcription factor," The Journal of Biological Chemistry, vol. 276, no. 1, pp. 35-39, 2001. 
[41] T. Subramanian and G. Chinnadurai, "Association of class I histone deacetylases with transcriptional corepressor CtBP," FEBS Letters, vol. 540, no. 1-3, pp. 255-258, 2003.

[42] Y. Shi, J. I. Sawada, G. Sui et al., "Coordinated histone modifications mediated by a CtBP co-repressor complex," Nature, vol. 422, no. 6933, pp. 735-738, 2003.

[43] O. G. McDonald, H. Wu, W. Timp, A. Doi, and A. P. Feinberg, "Genome-scale epigenetic reprogramming during epithelialto-mesenchymal transition," Nature Structural \& Molecular Biology, vol. 18, no. 8, pp. 867-874, 2011.

[44] J. Ueda, M. Tachibana, T. Ikura, and Y. Shinkai, "Zinc finger protein Wiz links G9a/GLP histone methyltransferases to the corepressor molecule CtBP," The Journal of Biological Chemistry, vol. 281, no. 29, pp. 20120-20128, 2006.

[45] J. H. Kim, E. J. Cho, S. T. Kim, and H. D. Youn, “CtBP represses p300-mediated transcriptional activation by direct association with its bromodomain," Nature Structural \& Molecular Biology, vol. 12, no. 5, pp. 423-428, 2005.

[46] Y. Zhang, X. Yang, B. Gui et al., "Corepressor protein CDYL functions as a molecular bridge between polycomb repressor complex 2 and repressive chromatin mark trimethylated histone lysine 27," The Journal of Biological Chemistry, vol. 286, no. 49, pp. 42414-42425, 2011.

[47] J. K. Pagan, J. Arnold, K. J. Hanchard et al., "A novel corepressor, BCoR-L1, represses transcription through an interaction with CtBP," The Journal of Biological Chemistry, vol. 282, no. 20, pp. 15248-15257, 2007.

[48] N. Vo, C. Fjeld, and R. H. Goodman, "Acetylation of nuclear hormone receptor-interacting protein RIP140 regulates binding of the transcriptional corepressor CtBP," Molecular and Cellular Biology, vol. 21, no. 18, pp. 6181-6188, 2001.

[49] B. H. A. Jack and M. Crossley, "GATA proteins work together with Friend of GATA (FOG) and C-terminal Binding Protein (CTBP) co-regulators to control adipogenesis," The Journal of Biological Chemistry, vol. 285, no. 42, pp. 32405-32414, 2010.

[50] S. Kajimura, P. Seale, T. Tomaru et al., "Regulation of the brown and white fat gene programs through a PRDM16/CtBP transcriptional complex," Genes and Development, vol. 22, no. 10, pp. 1397-1409, 2008.

[51] A. H. Mirnezami, S. J. Campbell, M. Darley, J. N. Primrose, P. W. M. Johnson, and J. P. Blaydes, "Hdm2 recruits a hypoxiasensitive corepressor to negatively regulate p53-dependent transcription," Current Biology, vol. 13, no. 14, pp. 1234-1239, 2003.

[52] S. Deltour, S. Pinte, C. Guerardel, B. Wasylyk, and D. Leprince, "The human candidate tumor suppressor gene $\mathrm{HIC1}$ recruits CtBP through a degenerate GLDLSKK motif," Molecular and Cellular Biology, vol. 22, no. 13, pp. 4890-4901, 2002.

[53] Q. Zhang, S. Y. Wang, C. Fleuriel et al., "Metabolic regulation of SIRT1 transcription via a HIC1:CtBP corepressor complex," Proceedings of the National Academy of Sciences of the United States of America, vol. 104, no. 3, pp. 829-833, 2007.

[54] L. M. Mendez, J. M. Polo, J. J. Yu et al., "CtBP is an essential corepressor for BCL6 autoregulation," Molecular and Cellular Biology, vol. 28, no. 7, pp. 2175-2186, 2008.

[55] N. Stankovic-Valentin, A. Verger, S. Deltour-Balerdi, K. G. R. Quinlan, M. Crossley, and D. Leprince, "A L225A substitution in the human tumour suppressor HICl abolishes its interaction with the corepressor CtBP," FEBS Journal, vol. 273, no. 13, pp. 2879-2890, 2006.
[56] A. Keutgens, K. Shostak, P. Close et al., "The repressing function of the oncoprotein BCL-3 requires $\mathrm{CtBP}$, while its polyubiquitination and degradation involve the E3 ligase TBLR1," Molecular and Cellular Biology, vol. 30, no. 16, pp. 4006-4021, 2010.

[57] A. Verger, K. G. R. Quinlan, L. A. Crofts et al., "Mechanisms directing the nuclear localization of the CtBP family proteins," Molecular and Cellular Biology, vol. 26, no. 13, pp. 4882-4894, 2006.

[58] J. Koipally and K. Georgopoulos, "Ikaros interactions with CtBP reveal a repression mechanism that is independent of histone deacetylase activity," The Journal of Biological Chemistry, vol. 275, no. 26, pp. 19594-19602, 2000.

[59] R. Alpatov, G. C. Munguba, P. Caton et al., "Nuclear speckleassociated protein Pnn/DRS binds to the transcriptional corepressor CtBP and relieves CtBP-mediated repression of the Ecadherin gene," Molecular and Cellular Biology, vol. 24, no. 23, pp. 10223-10235, 2004.

[60] X. Lin, Y. Y. Liang, B. Sun et al., "Smad6 recruits transcription corepressor CtBP to repress bone morphogenetic proteininduced transcription," Molecular and Cellular Biology, vol. 23, no. 24, pp. 9081-9093, 2003.

[61] J. Sierra, T. Yoshida, C. A. Joazeiro, and K. A. Jones, "The APC tumor suppressor counteracts $\beta$-catenin activation and H3K4 methylation at Wnt target genes," Genes and Development, vol. 20, no. 5, pp. 586-600, 2006.

[62] L. D. Nadauld, R. Phelps, B. C. Moore et al., "Adenomatous polyposis coli control of C-terminal binding protein-1 stability regulates expression of intestinal retinol dehydrogenases," The Journal of Biological Chemistry, vol. 281, no. 49, pp. 37828-37835, 2006.

[63] R. A. Phelps, S. Chidester, S. Dehghanizadeh et al., "A two-step model for colon adenoma initiation and progression caused by APC loss," Cell, vol. 137, no. 4, pp. 623-634, 2009.

[64] S. Paliwal, S. Pande, R. C. Kovi, N. E. Sharpless, N. Bardeesy, and S. R. Grossman, "Targeting of C-terminal binding protein (CtBP) by ARF results in p53-independent apoptosis," Molecular and Cellular Biology, vol. 26, no. 6, pp. 2360-2372, 2006.

[65] Q. Zhang, A. Nottke, and R. H. Goodman, "Homeodomaininteracting protein kinase-2 mediates CtBP phosphorylation and degradation in UV-triggered apoptosis," Proceedings of the National Academy of Sciences of the United States of America, vol. 102, no. 8, pp. 2802-2807, 2005.

[66] S. Y. Wang, M. Iordanov, and Q. Zhang, "c-Jun NH2-terminal kinase promotes apoptosis by down-regulating the transcriptional co-repressor CtBP," The Journal of Biological Chemistry, vol. 281, no. 46, pp. 34810-34815, 2006.

[67] V. Perissi, C. Scafoglio, J. Zhang et al., "TBL1 and TBLR1 phosphorylation on regulated gene promoters overcomes dual CtBP and NCoR/SMRT transcriptional repression checkpoints," Molecular Cell, vol. 29, no. 6, pp. 755-766, 2008.

[68] Y. Wang, F. Liu, F. Mao et al., "Interaction with CCNH/CDK7 stabilizes CtBP2 and promotes cancer cell migration," The Journal of Biological Chemistry, vol. 288, no. 13, pp. 9028-9034, 2013.

[69] K. B. Kegel, A. R. Meloni, Y. Yi et al., "Huntingtin is present in the nucleus, interacts with the transcriptional corepressor C-terminal binding protein, and represses transcription," The Journal of Biological Chemistry, vol. 277, no. 9, pp. 7466-7476, 2002.

[70] S. C. Kim, Y. S. Kim, and A. M. Jetten, "Krüppel-like zinc finger protein Gli-similar 2 (Glis2) represses transcription through 
interaction with C-terminal binding protein 1 (CtBP1)," Nucleic Acids Research, vol. 33, no. 21, pp. 6805-6815, 2005.

[71] Y. Haga, N. Miwa, S. Jahangeer, T. Okada, and S. I. Nakamura, "CtBP1/BARS is an activator of phospholipase D1 necessary for agonist-induced macropinocytosis," EMBO Journal, vol. 28, no. 9, pp. 1197-1207, 2009.

[72] D. L. Madison and J. R. Lundblad, "C-terminal binding protein and poly(ADP)ribose polymerase 1 contribute to repression of the p21waf1/cip1 promoter," Oncogene, vol. 29, no. 45, pp. 60276039, 2010.

[73] A. Murakami, S. Ishida, J. Thurlow, J. M. Revest, and C. Dickson, "SOX6 binds CtBP2 to repress transcription from the Fgf-3 promoter," Nucleic Acids Research, vol. 29, no. 16, pp. 3347-3355, 2001.

[74] F. Oswald, M. Winkler, Y. Cao et al., "RBP-J $/$ /SHARP recruits CtIP/CtBP corepressors to silence notch target genes," Molecular and Cellular Biology, vol. 25, no. 23, pp. 10379-10390, 2005.

[75] J. Perdomo and M. Crossley, "The Ikaros family protein Eos associates with C-terminal-binding protein corepressors," European Journal of Biochemistry, vol. 269, no. 23, pp. 5885-5892, 2002.

[76] C. Perry, M. Pick, E. Podoly et al., "Acetylcholinesterase/C terminal binding protein interactions modify Ikaros functions, causing T lymphopenia," Leukemia, vol. 21, no. 7, pp. 1472-1480, 2007.

[77] P. K. Purbey, S. Singh, D. Notani, P. P. Kumar, A. S. Limaye, and S. Galande, "Acetylation-dependent interaction of SATB1 and CtBP1 mediates transcriptional repression by SATB1," Molecular and Cellular Biology, vol. 29, no. 5, pp. 1321-1337, 2009.

[78] G. M. Riefler and B. L. Firestein, "Binding of neuronal nitricoxide synthase (nNOS) to carboxyl-terminal-binding protein (CtBP) changes the localization of ctbp from the nucleus to the cytosol: a novel function for targeting by the PDZ domain of nNOS," The Journal of Biological Chemistry, vol. 276, no. 51, pp. 48262-48268, 2001.

[79] M. G. Roukens, M. Alloul-Ramdhani, B. Baan et al., "Control of endothelial sprouting by a Tel-CtBP complex," Nature Cell Biology, vol. 12, no. 10, pp. 933-942, 2010.

[80] K. Saijo, J. G. Collier, A. C. Li, J. A. Katzenellenbogen, and C. K. Glass, "An ADIOL-ER $\beta$-CtBP transrepression pathway negatively regulates microglia-mediated inflammation," Cell, vol. 145, no. 4, pp. 584-595, 2011.

[81] M. Schuierer, K. Hilger-Eversheim, T. Dobner et al., "Induction of AP- $2 \alpha$ expression by adenoviral infection involves inactivation of the AP-2rep transcriptional corepressor CtBP1," The Journal of Biological Chemistry, vol. 276, no. 30, pp. 2794427949, 2001.

[82] Z. B. Xia, M. Anderson, M. O. Diaz, and N. J. Zeleznik-Le, "MLL repression domain interacts with histone deacetylases, the polycomb group proteins HPC2 and BMI-1, and the corepressor Cterminal-binding protein," Proceedings of the National Academy of Sciences of the United States of America, vol. 100, no. 14, pp. 8342-8347, 2003.

[83] J. Yang and A. D. Everett, "Hepatoma-derived growth factor represses SET and MYND domain containing 1 gene expression through interaction with C-terminal binding protein," Journal of Molecular Biology, vol. 386, no. 4, pp. 938-950, 2009.

[84] N. F. Zaidi, K. G. Kuplast, K. J. Washicosky, Y. Kajiwara, J. D. Buxbaum, and W. Wasco, "Calsenilin interacts with transcriptional co-repressor C-terminal binding protein(s)," Journal of Neurochemistry, vol. 98, no. 4, pp. 1290-1301, 2006.
[85] F. Hamada and M. Bienz, "The APC tumor suppressor binds to $\mathrm{C}$-terminal binding protein to divert nuclear $\beta$-catenin from TCF," Developmental Cell, vol. 7, no. 5, pp. 677-685, 2004.

[86] Q. Zhang, Y. Yoshimatsu, J. Hildebrand, S. M. Frisch, and R. H. Goodman, "Homeodomain interacting protein kinase 2 promotes apoptosis by downregulating the transcriptional corepressor CtBP," Cell, vol. 115, no. 2, pp. 177-186, 2003.

[87] F. Zou, J. Xu, H. Fu et al., "Different functions of HIPK2 and CtBP2 in traumatic brain injury," Journal of Molecular Neuroscience, vol. 49, no. 2, pp. 395-408, 2013.

[88] V. Perissi, C. Scafoglio, J. Zhang et al., “TBL1 and TBLR1 phosphorylation on regulated gene promoters overcomes dual CtBP and NCoR/SMRT transcriptional repression checkpoints," Molecular Cell, vol. 29, no. 6, pp. 755-766, 2008.

[89] R. C. Kovi, S. Paliwal, S. Pande, and S. R. Grossman, "An $\mathrm{ARF} / \mathrm{CtBP} 2$ complex regulates $\mathrm{BH} 3$-only gene expression and p53-independent apoptosis," Cell Death and Differentiation, vol. 17, no. 3, pp. 513-521, 2010.

[90] Y. W. Chen, S. Paliwal, K. Draheim, S. R. Grossman, and B. C. Lewis, "P19Arf inhibits the invasion of hepatocellular carcinoma cells by binding to c-terminal binding protein," Cancer Research, vol. 68, no. 2, pp. 476-482, 2008.

[91] H. J. Choi, J. M. Lee, H. Kim et al., "Bcl3-dependent stabilization of CtBP1 is crucial for the inhibition of apoptosis and tumor progression in breast cancer," Biochemical and Biophysical Research Communications, vol. 400, no. 3, pp. 396-402, 2010.

[92] E. B. Dammer and M. B. Sewer, "Phosphorylation of CtBP1 by cAMP-dependent protein kinase modulates induction of CYP17 by stimulating partnering of CtBP1 and 2," The Journal of Biological Chemistry, vol. 283, no. 11, pp. 6925-6934, 2008.

[93] J. H. Kim, S. Y. Choi, B. H. Kang et al., "AMP-activated protein kinase phosphorylates CtBP1 and down-regulates its activity," Biochemical and Biophysical Research Communications, vol. 431, no. 1, pp. 8-13, 2013.

[94] J. S. Lee, S. K. Lee, H. D. Youn, and S. J. Yoo, "C-terminal binding protein-mediated transcriptional repression is regulated by $\mathrm{X}$ linked inhibitor of apoptosis protein," Biochemical and Biophysical Research Communications, vol. 417, no. 1, pp. 175-181, 2012.

[95] J. S. Lee and S. J. Yoo, "C-terminus of Hsc70-interacting protein regulates C-terminal binding protein 2 and the expression of its target genes," Biochemical and Biophysical Research Communications, vol. 432, no. 3, pp. 418-424, 2013.

[96] J. C. Merrill, M. H. Kagey, T. A. Melhuish, S. E. Powers, B. J. Zerlanko, and D. Wotton, "Inhibition of CtBP1 activity by Aktmediated phosphorylation," Journal of Molecular Biology, vol. 398, no. 5, pp. 657-671, 2010.

[97] C. J. Barnes, R. K. Vadlamudi, S. K. Mishra, R. H. Jacobson, F. $\mathrm{Li}$, and R. Kumar, "Functional inactivation of a transcriptional corepressor by a signaling kinase," Nature Structural Biology, vol. 10, no. 8, pp. 622-628, 2003.

[98] X. Lin, B. Sun, M. Liang et al., "Opposed regulation of corepressor CtBP by SUMOylation and PDZ binding," Molecular Cell, vol. 11, no. 5, pp. 1389-1396, 2003.

[99] J. C. Merrill, T. A. Melhuish, M. H. Kagey, S. H. Yang, A. D. Sharrocks, and D. Wotton, "A role for non-covalent SUMO interaction motifs in Pc2/CBX4 E3 activity," PLoS ONE, vol. 5, no. 1, Article ID e8794, 2010.

[100] M. H. Kagey, T. A. Melhuish, S. E. Powers, and D. Wotton, "Multiple activities contribute to Pc2 E3 function," EMBO Journal, vol. 24, no. 1, pp. 108-119, 2005.

[101] M. H. Kagey, T. A. Melhuish, and D. Wotton, "The polycomb protein Pc2 is a SUMO E3,” Cell, vol. 113, no. 1, pp. 127-137, 2003. 
[102] L. J. Zhao, T. Subramanian, Y. Zhou, and G. Chinnadurai, "Acetylation by $\mathrm{p} 300$ regulates nuclear localization and function of the transcriptional corepressor CtBP2," The Journal of Biological Chemistry, vol. 281, no. 7, pp. 4183-4189, 2006.

[103] O. Warburg, "On the origin of cancer cells," Science, vol. 123, no. 3191, pp. 309-314, 1956.

[104] O. Warburg, "On respiratory impairment in cancer cells," Science, vol. 124, no. 3215, pp. 269-270, 1956.

[105] O. Warburg, F. Wind, and E. Negelein, "The metabolism of tumors in the body," The Journal of General Physiology, vol. 8, no. 6, pp. 519-530, 1927.

[106] C. V. Dang, M. Hamaker, P. Sun, A. Le, and P. Gao, "Therapeutic targeting of cancer cell metabolism," Journal of Molecular Medicine, vol. 89, no. 3, pp. 205-212, 2011.

[107] J. W. Kim and C. V. Dang, "Cancer's molecular sweet tooth and the warburg effect," Cancer Research, vol. 66, no. 18, pp. 89278930, 2006.

[108] W. H. Koppenol, P. L. Bounds, and C. V. Dang, "Otto Warburg's contributions to current concepts of cancer metabolism," Nature Reviews Cancer, vol. 11, no. 5, pp. 325-337, 2011.

[109] T. Bui and C. B. Thompson, "Cancer's sweet tooth," Cancer Cell, vol. 9, no. 6, pp. 419-420, 2006.

[110] R. J. DeBerardinis, J. J. Lum, G. Hatzivassiliou, and C. B. Thompson, "The biology of cancer: metabolic reprogramming fuels cell growth and proliferation," Cell Metabolism, vol. 7, no. 1, pp. 11-20, 2008.

[111] M. G. Vander Heiden, L. C. Cantley, and C. B. Thompson, "Understanding the warburg effect: the metabolic requirements of cell proliferation," Science, vol. 324, no. 5930, pp. 1029-1033, 2009.

[112] J. P. Silva and C. Wahlestedt, "Role of Sirtuin 1 in metabolic regulation,” Drug Discovery Today, vol. 15, no. 17-18, pp. 781-791, 2010.

[113] S. Kyrylenko and A. Baniahmad, "Sirtuin family: a link to metabolic signaling and senescence," Current Medicinal Chemistry, vol. 17, no. 26, pp. 2921-2932, 2010.

[114] A. Bürkle, "DNA repair and PARP in aging," Free Radical Research, vol. 40, no. 12, pp. 1295-1302, 2006.

[115] A. Aly and S. Ganesan, "BRCA1, PARP, and 53BP1: conditional synthetic lethality and synthetic viability," Journal of Molecular Cell Biology, vol. 3, no. 1, pp. 66-74, 2011.

[116] R. Krishnakumar and W. L. Kraus, "The PARP side of the nucleus: molecular actions, physiological outcomes, and clinical targets," Molecular Cell, vol. 39, no. 1, pp. 8-24, 2010.

[117] G. Chinnadurai, "CtBP, an unconventional transcriptional torepressor in development and oncogenesis," Molecular Cell, vol. 9, no. 2, pp. 213-224, 2002.

[118] G. Chinnadurai, "CtBP family proteins: more than transcriptional corepressors," BioEssays, vol. 25, no. 1, pp. 9-12, 2003.

[119] G. Chinnadurai, "Transcriptional regulation by C-terminal binding proteins," International Journal of Biochemistry and Cell Biology, vol. 39, no. 9, pp. 1593-1607, 2007.

[120] G. Chinnadurai, "The transcriptional corepressor CtBP: a foe of multiple tumor suppressors," Cancer Research, vol. 69, no. 3, pp. 731-734, 2009.

[121] E. Verdin, M. D. Hirschey, L. W. S. Finley, and M. C. Haigis, "Sirtuin regulation of mitochondria: energy production, apoptosis, and signaling," Trends in Biochemical Sciences, vol. 35, no. 12, pp. 669-675, 2010.
[122] Q. Zhang, D. W. Piston, and R. H. Goodman, "Regulation of corepressor function by nuclear NADH," Science, vol. 295, no. 5561, pp. 1895-1897, 2002.

[123] J. M. Boyd, T. Subramanian, U. Schaeper, M. La Regina, S. Bayley, and G. Chinnadurai, "A region in the C-terminus of adenovirus 2/5 Ela protein is required for association with a cellular phosphoprotein and important for the negative modulation of T24-ras mediated transformation tumorigenesis and metastasis," EMBO Journal, vol. 12, no. 2, pp. 469-478, 1993.

[124] K. Sollerbrant, G. Chinnadurai, and C. Svensson, “The CtBP binding domain in the adenovirus E1A protein controls CR1dependent transactivation," Nucleic Acids Research, vol. 24, no. 13, pp. 2578-2584, 1996.

[125] D. P. Molloy, A. E. Milner, I. K. Yakub, G. Chinnadurai, P. H. Gallimore, and R. J. A. Grand, "Structural determinants present in the C-terminal binding protein binding site of adenovirus early region 1A proteins," The Journal of Biological Chemistry, vol. 273, no. 33, pp. 20867-20876, 1998.

[126] A. A. Postigo and D. C. Dean, "ZEB represses transcription through interaction with the corepressor CtBP," Proceedings of the National Academy of Sciences of the United States of America, vol. 96, no. 12, pp. 6683-6688, 1999.

[127] U. Schaeper, T. Subramanian, L. Lim, J. M. Boyd, and G. Chinnadurai, "Interaction between a cellular protein that binds to the C-terminal region of adenovirus E1A (CtBP) and a novel cellular protein is disrupted by E1A through a conserved PLDLS motif," The Journal of Biological Chemistry, vol. 273, no. 15, pp. 8549-8552, 1998.

[128] N. Minamisawa et al., "ANGUSTIFOLIA, a plant homolog of CtBP/BARS, functions outside the nucleus," The Plant Journal, vol. 68 , no. 5, pp. 788-799, 2011.

[129] S. Chen, J. R. Whetstine, S. Ghosh et al., "The conserved $\mathrm{NAD}(\mathrm{H})$-dependent corepressor CTBP-1 regulates Caenorhabditis elegans life span," Proceedings of the National Academy of Sciences of the United States of America, vol. 106, no. 5, pp. 14961501, 2009.

[130] M. L. Grooteclaes and S. M. Frisch, "Evidence for a function of CtBP in epithelial gene regulation and anoikis," Oncogene, vol. 19, no. 33, pp. 3823-3828, 2000.

[131] R. Kalluri and R. A. Weinberg, "The basics of epithelialmesenchymal transition," The Journal of Clinical Investigation, vol. 119, no. 6, pp. 1420-1428, 2009.

[132] R. M. Glasspool, S. Burns, S. F. Hoare, C. Svensson, and W. N. Keith, "The hTERT and hTERC telomerase gene promoters are activated by the second exon of the adenoviral protein, E1A, identifying the transcriptional corepressor CtBP as a potential repressor of both genes," Neoplasia, vol. 7, no. 6, pp. 614-622, 2005.

[133] M. Garriga-Canut, B. Schoenike, R. Qazi et al., “2-Deoxy-Dglucose reduces epilepsy progression by NRSF-CtBP-dependent metabolic regulation of chromatin structure," Nature Neuroscience, vol. 9, no. 11, pp. 1382-1387, 2006.

[134] Y. Drabsch and P. Ten Dijke, "TGF-beta signalling and its role in cancer progression and metastasis," Cancer and Metastasis Reviews, no. 3-4, pp. 553-568, 2012.

[135] S. Palmer, J. P. Brouillet, A. Kilbey et al., "Evi-1 transforming and repressor activities are mediated by CtBP co-repressor proteins," The Journal of Biological Chemistry, vol. 276, no. 28, pp. 2583425840, 2001.

[136] K. Izutsu, M. Kurokawa, Y. Imai et al., “The t(3;21) fusion product, AML1/Evi-1 blocks AML1-induced transactivation by recruiting CtBP," Oncogene, vol. 21, no. 17, pp. 2695-2703, 2002. 
[137] V. Senyuk, S. Chakraborty, F. M. Mikhail, R. Zhao, Y. Chi, and G. Nucifora, "The leukemia-associated transcription repressor AML1/MDS1/EVI1 requires CtBP to induce abnormal growth and differentiation of murine hematopoietic cells," Oncogene, vol. 21, no. 20, pp. 3232-3240, 2002.

[138] J. D. Hildebrand and P. Soriano, "Overlapping and unique roles for C-terminal binding protein 1 (CtBP1) and CtBP2 during mouse development," Molecular and Cellular Biology, vol. 22, no. 15, pp. 5296-5307, 2002.

[139] V. Kumar, J. E. Carlson, K. A. Ohgi et al., "Transcription corepressor CtBP is an NAD+-regulated dehydrogenase," Molecular Cell, vol. 10, no. 4, pp. 857-869, 2002.

[140] P. Balasubramanian, L. J. Zhao, and G. Chinnadurai, "Nicotinamide adenine dinucleotide stimulates oligomerization, interaction with adenovirus E1A and an intrinsic dehydrogenase activity of CtBP," FEBS Letters, vol. 537, no. 1-3, pp. 157-160, 2003.

[141] C. C. Fjeld, W. T. Birdsong, and R. H. Goodman, "Differential binding of NAD+ and NADH allows the transcriptional corepressor carboxyl-terminal binding protein to serve as a metabolic sensor," Proceedings of the National Academy of Sciences of the United States of America, vol. 100, no. 16, pp. 9202-9207, 2003.

[142] M. Sutrias-Grau and D. N. Arnosti, "CtBP contributes quantitatively to Knirps repression activity in an NAD bindingdependent manner," Molecular and Cellular Biology, vol. 24, no. 13, pp. 5953-5966, 2004.

[143] Y. W. Zhang and D. N. Arnosti, "Conserved catalytic and C-terminal regulatory domains of the C-terminal binding protein corepressor fine-tune the transcriptional response in development," Molecular and Cellular Biology, vol. 31, no. 2, pp. 375-384, 2011.

[144] T. Subramanian and G. Chinnadurai, "Association of class I histone deacetylases with transcriptional corepressor CtBP," FEBS Letters, vol. 540, no. 1-3, pp. 255-258, 2003.

[145] Y. Chang, L. Sun, K. Kokura et al., "MPP8 mediates the interactions between DNA methyltransferase Dnmt3a and H3K9 methyltransferase GLP/G9a," Nature Communications, vol. 2, article 533, 2011.

[146] D. C. Leung, K. B. Dong, I. A. Maksakova et al., "Lysine methyltransferase G9a is required for de novo DNA methylation and the establishment, but not the maintenance, of proviral silencing," Proceedings of the National Academy of Sciences of the United States of America, vol. 108, no. 14, pp. 5718-5723, 2011.

[147] B. Li, J. Zhou, P. Liu et al., "Polycomb protein Cbx4 promotes SUMO modification of de novo DNA methyltransferase Dnmt3a," Biochemical Journal, vol. 405, no. 2, pp. 369-378, 2007.

[148] Y. Oma, K. Nishimori, and M. Harata, "The brain-specific actinrelated protein $\mathrm{ArpN} \alpha$ interacts with the transcriptional corepressor CtBP," Biochemical and Biophysical Research Communications, vol. 301, no. 2, pp. 521-528, 2003.

[149] S. Deltour, S. Pinte, C. Guerardel, B. Wasylyk, and D. Leprince, "The human candidate tumor suppressor gene HIC1 recruits CtBP through a degenerate GLDLSKK motif," Molecular and Cellular Biology, vol. 22, no. 13, pp. 4890-4901, 2002.

[150] J. Lopez-Garcia, M. Periyasamy, R. S. Thomas et al., "ZNF366 is an estrogen receptor corepressor that acts through CtBP and histone deacetylases," Nucleic Acids Research, vol. 34, no. 21, pp. 6126-6136, 2006.

[151] P. Cuilliere-Dartigues, J. El-Bchiri, A. Krimi et al., "TCF-4 isoforms absent in TCF-4 mutated MSI-H colorectal cancer cells colocalize with nuclear CtBP and repress TCF-4-mediated transcription," Oncogene, vol. 25, no. 32, pp. 4441-4448, 2006.

[152] R. Alpatov, Y. Shi, G. C. Munguba et al., "Corepressor CtBP and nuclear speckle protein Pnn/DRS differentially modulate transcription and splicing of the E-cadherin gene," Molecular and Cellular Biology, vol. 28, no. 5, pp. 1584-1595, 2008.

[153] L. J. Zhao, T. Subramanian, Y. Zhou, and G. Chinnadurai, "Acetylation by p300 regulates nuclear localization and function of the transcriptional corepressor CtBP2," The Journal of Biological Chemistry, vol. 281, no. 7, pp. 4183-4189, 2006.

[154] M. H. Kagey, T. A. Melhuish, S. E. Powers, and D. Wotton, "Multiple activities contribute to Pc2 E3 function," EMBO Journal, vol. 24, no. 1, pp. 108-119, 2005.

[155] M. H. Kagey, T. A. Melhuish, and D. Wotton, “The polycomb protein Pc2 is a SUMO E3," Cell, vol. 113, no. 1, pp. 127-137, 2003.

[156] J. C. Merrill, M. H. Kagey, T. A. Melhuish, S. E. Powers, B. J. Zerlanko, and D. Wotton, "Inhibition of CtBP1 activity by Aktmediated phosphorylation," Journal of Molecular Biology, vol. 398, no. 5, pp. 657-671, 2010.

[157] S. Paliwal, S. Pande, R. C. Kovi, N. E. Sharpless, N. Bardeesy, and S. R. Grossman, "Targeting of C-terminal binding protein (CtBP) by ARF results in p53-independent apoptosis," Molecular and Cellular Biology, vol. 26, no. 6, pp. 2360-2372, 2006.

[158] C. Valente, G. Turacchio, S. Mariggio et al., "A 14-3-3gamma dimer-based scaffold bridges CtBP1-S/BARS to PI(4)KIIIbeta to regulate post-Golgi carrier formation," Nature Cell Biology, vol. 14, no. 4, pp. 343-354, 2012.

[159] M. Bonazzi, S. Spanò, G. Turacchio et al., "CtBP3/BARS drives membrane fission in dynamin-independent transport pathways," Nature Cell Biology, vol. 7, no. 6, pp. 570-580, 2005.

[160] C. Hidalgo Carcedo, M. Donazzi, S. Spano et al., "Mitotic Golgi partitioning is driven by the membrane-fissioning protein CtBP3/BARS," Science, vol. 305, no. 5680, pp. 93-96, 2004.

[161] R. Welgert, M. G. Silletta, S. Spanò et al., "CtBP/BARS induces fission of Golgi membranes by acylating lysophosphatidic acid," Nature, vol. 402, no. 6760, pp. 429-433, 1999.

[162] J. L. Gallop, P. J. G. Butler, and H. T. McMahon, "Endophilin and CtBP/BARS are not acyl transferases in endocytosis or Golgi fission," Nature, vol. 438, no. 7068, pp. 675-678, 2005.

[163] D. Corda, A. Colanzi, and A. Luini, "The multiple activities of CtBP/BARS proteins: the Golgi view," Trends in Cell Biology, vol. 16, no. 3, pp. 167-173, 2006.

[164] I. Monleón, M. Iturralde, M. J. Martínez-Lorenzo et al., "Lack of Fas/CD95 surface expression in highly proliferative leukemic cell lines correlates with loss of CtBP/BARS and redirection of the protein toward giant lysosomal structures," Cell Growth and Differentiation, vol. 13, no. 7, pp. 315-324, 2002.

[165] D. St Johnston and B. Sanson, "Epithelial polarity and morphogenesis," Current Opinion in Cell Biology, vol. 23, no. 5, pp. 540546, 2011.

[166] F. Martin-Belmonte and M. Perez-Moreno, "Epithelial cell polarity, stem cells and cancer," Nature Reviews Cancer, vol. 12, no. 1, pp. 23-38, 2012.

[167] L. M. McCaffrey and I. G. Macara, "Epithelial organization, cell polarity and tumorigenesis," Trends in Cell Biology, vol. 21, no. 12, pp. 727-735, 2011.

[168] M. Spyer and M. J. Allday, "The transcriptional co-repressor Cterminal Binding Protein (CtBP) associates with centrosomes during mitosis," Cell Cycle, vol. 5, no. 5, pp. 530-537, 2006.

[169] C. Kelsom and W. Lu, "Uncovering the link between malfunctions in Drosophila neuroblast asymmetric cell division and tumorigenesis," Cell \& Bioscience, vol. 2, article 38, 2012. 
[170] J. W. Snow, J. Kim, C. R. Currie, J. Xu, and S. H. Orkin, "Sumoylation regulates interaction of FOG1 with C-terminalbinding protein (CTBP)," The Journal of Biological Chemistry, vol. 285, no. 36, pp. 28064-28075, 2010.

[171] K. Morishita, "Role of CtBP-binding transcription factors in leukemogenesis," Rinsho Ketsueki, vol. 50, no. 3, pp. 160-167, 2009.

[172] M. W. Straza, S. Paliwal, R. C. Kovi et al., "Therapeutic targeting of C-terminal binding protein in human cancer," Cell Cycle, vol. 9, no. 18, pp. 3740-3750, 2010.

[173] J. Schneikert, K. Brauburger, and J. Behrens, "APC mutations in colorectal tumours from FAP patients are selected for CtBPmediated oligomerization of truncated APC," Human Molecular Genetics, vol. 20, no. 18, pp. 3554-3564, 2011.

[174] C. Peña, J. M. García, V. García et al., “The expression levels of the transcriptional regulators p300 and CtBP modulate the correlations between SNAIL, ZEB1, E-cadherin and vitamin D receptor in human colon carcinomas," International Journal of Cancer, vol. 119, no. 9, pp. 2098-2104, 2006.

[175] Q. Zhang, S. Y. Wang, A. C. Nottke, J. V. Rocheleau, D. W. Piston, and R. H. Goodman, "Redox sensor CtBP mediates hypoxiainduced tumor cell migration," Proceedings of the National Academy of Sciences of the United States of America, vol. 103, no. 24, pp. 9029-9033, 2006.

[176] H. Deng, J. Liu, Y. Deng et al., "CtBP1 is expressed in Melanoma and represses the transcription of p16INK4a and Brcal," Journal of Investigative Dermatology, vol. 133, no. 5, pp. 1294-1301, 2013.

[177] Y. Deng, J. Liu, G. Han et al., "Redox-dependent Brcal transcriptional regulation by an NADH-sensor CtBP1," Oncogene, vol. 29, no. 50, pp. 6603-6608, 2010.

[178] C. Guan, H. Shi, H. Wang et al., "CtBP2 contributes to malignant development of human esophageal squamous cell carcinoma by regulation of p16(INK4A.)," Journal of Cellular Biochemistry, vol. 114, no. 6, pp. 1343-1354, 2013.

[179] L. Barroilhet, J. Yang, K. Hasselblatt et al., "C-terminal binding protein-2 regulates response of epithelial ovarian cancer cells to histone deacetylase inhibitors," Oncogene, 2012.

[180] R. Wang, I. A. Asangani, B. V. Chakravarthi et al., "Role of transcriptional corepressor CtBP1 in prostate cancer progression," Neoplasia, vol. 14, no. 10, pp. 905-914, 2012.

[181] C. N. Birts, R. Harding, G. Soosaipillai et al., "Expression of CtBP family protein isoforms in breast cancer and their role in chemoresistance," Biology of the Cell, vol. 103, no. 1, pp. 1-19, 2011.

[182] L.-J. Di, A. G. Fernandez, A. De Siervi, D. L. Longo, and K. Gardner, "Transcriptional regulation of BRCA1 expression by a metabolic switch," Nature Structural \& Molecular Biology, vol. 17, no. 12, pp. 1406-1413, 2010.

[183] L. Z. Zhao and G. Chinnadurai, "Incapacitating CtBP to kill cancer," Cell Cycle, vol. 9, no. 18, pp. 3645-3646, 2010.

[184] Y. Deng, H. Deng, J. Liu et al., "Transcriptional down-regulation of Brcal and E-cadherin by CtBP1 in breast cancer," Molecular Carcinogenesis, vol. 51, no. 6, pp. 500-507, 2012.

[185] L. J. Di, J. S. Byun, M. M. Wong et al., "Genome-wide profiles of CtBP link metabolism with genome stability and epithelial reprogramming in breast cancer," Nature Communications, vol. 4, article 1449, 2013.

[186] D. Hanahan and R. A. Weinberg, "The hallmarks of cancer," Cell, vol. 100, no. 1, pp. 57-70, 2000.

[187] S. Valastyan and R. A. Weinberg, "Tumor metastasis: molecular insights and evolving paradigms," Cell, vol. 147, no. 2, pp. 275292, 2011.
[188] Z. Hu, C. Fan, D. S. Oh et al., "The molecular portraits of breast tumors are conserved across microarray platforms," BMC Genomics, vol. 7, article 96, 2006.

[189] C. M. Perou, T. Sørile, M. B. Eisen et al., "Molecular portraits of human breast tumours," Nature, vol. 406, no. 6797, pp. 747-752, 2000.

[190] T. C. G. A. Network, "Comprehensive molecular portraits of human breast tumours," Nature, vol. 490, no. 7418, pp. 61-70, 2012.

[191] A. Prat, J. S. Parker, O. Karginova et al., "Phenotypic and molecular characterization of the claudin-low intrinsic subtype of breast cancer," Breast Cancer Research, vol. 12, no. 5, article R68, 2010.

[192] R. C. Millikan, B. Newman, C. K. Tse et al., "Epidemiology of basal-like breast cancer," Breast Cancer Research and Treatment, vol. 109, no. 1, pp. 123-139, 2008.

[193] J. I. Herschkowitz, W. Zhao, M. Zhang et al., "Comparative oncogenomics identifies breast tumors enriched in functional tumor-initiating cells," Proceedings of the National Academy of Sciences of the United States of America, vol. 109, no. 8, pp. 27782783, 2012.

[194] C. A. Livasy, G. Karaca, R. Nanda et al., "Phenotypic evaluation of the basal-like subtype of invasive breast carcinoma," Modern Pathology, vol. 19, no. 2, pp. 264-271, 2006.

[195] M. Koh, J. C. Lee, C. Min, and A. Moon, "A novel metformin derivative, HL010183, inhibits proliferation and invasion of triple-negative breast cancer cells," Bioorganic \& Medicinal Chemistry, vol. 21, no. 8, pp. 2305-2313, 2013.

[196] S. Gandini, A. Guerrieri-Gonzaga, M. Puntoni, and A. DeCensi, "Metformin and breast cancer risk," Journal of Clinical Oncology, vol. 31, no. 7, pp. 973-974, 2013. 

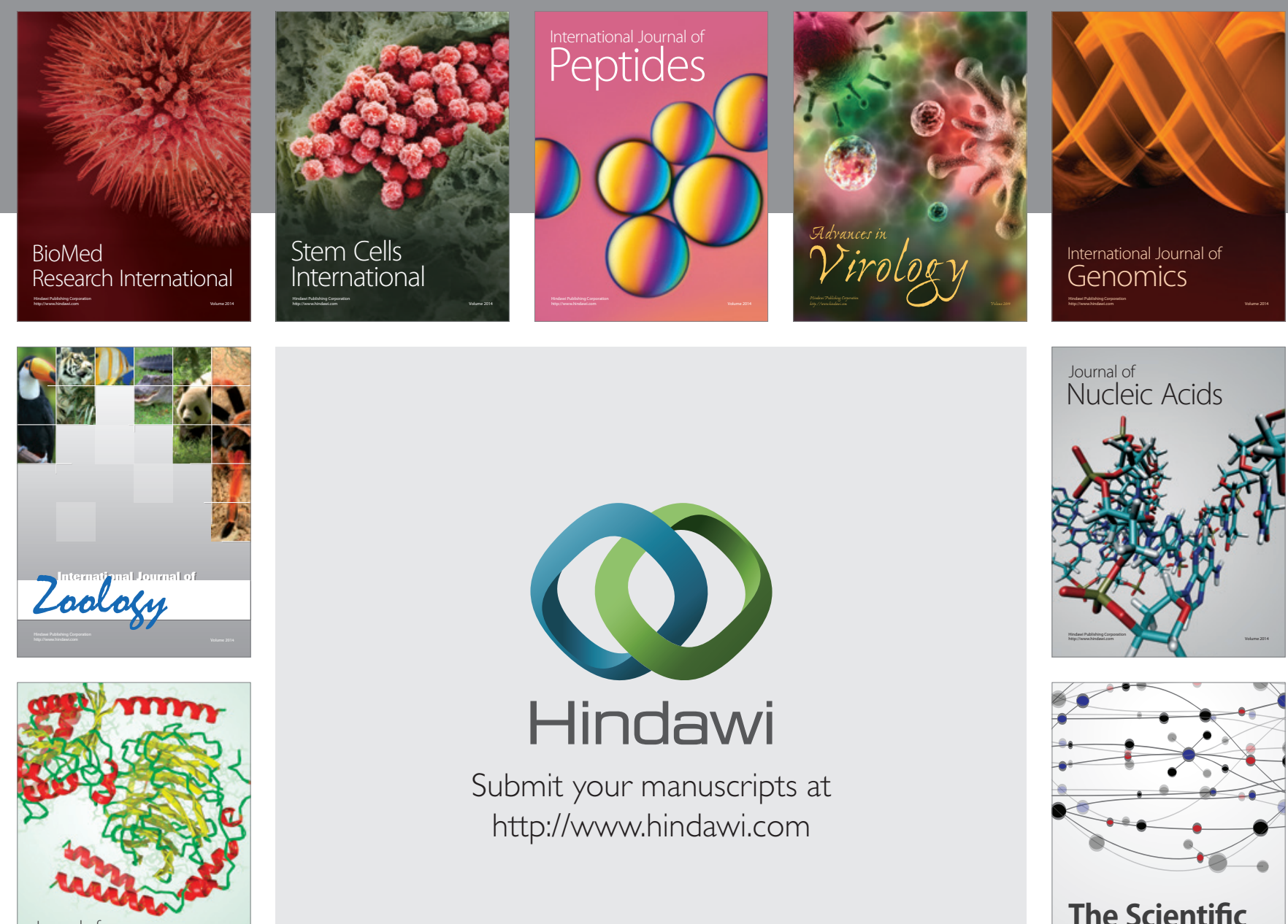

Submit your manuscripts at

http://www.hindawi.com

Journal of
Signal Transduction
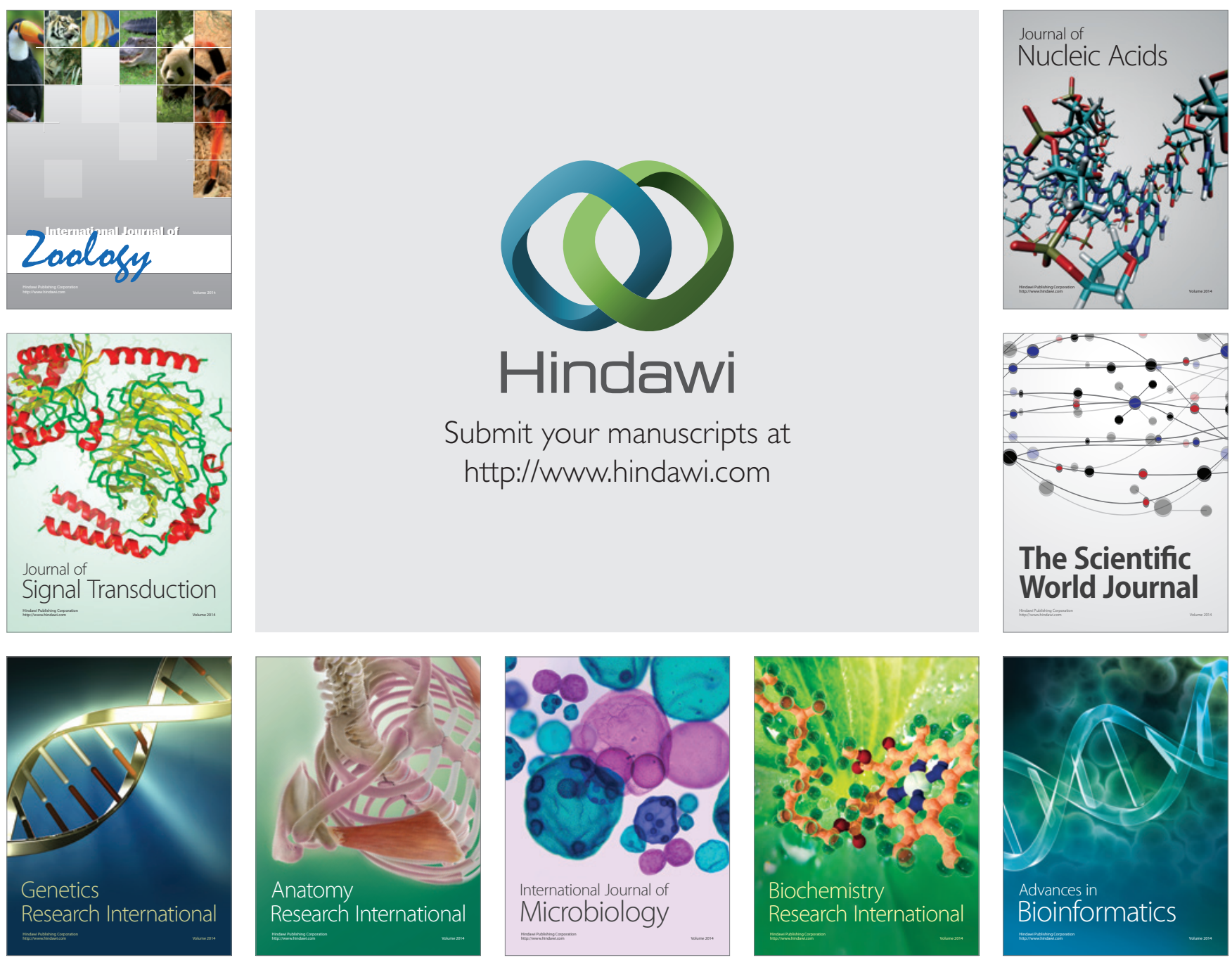

The Scientific World Journal
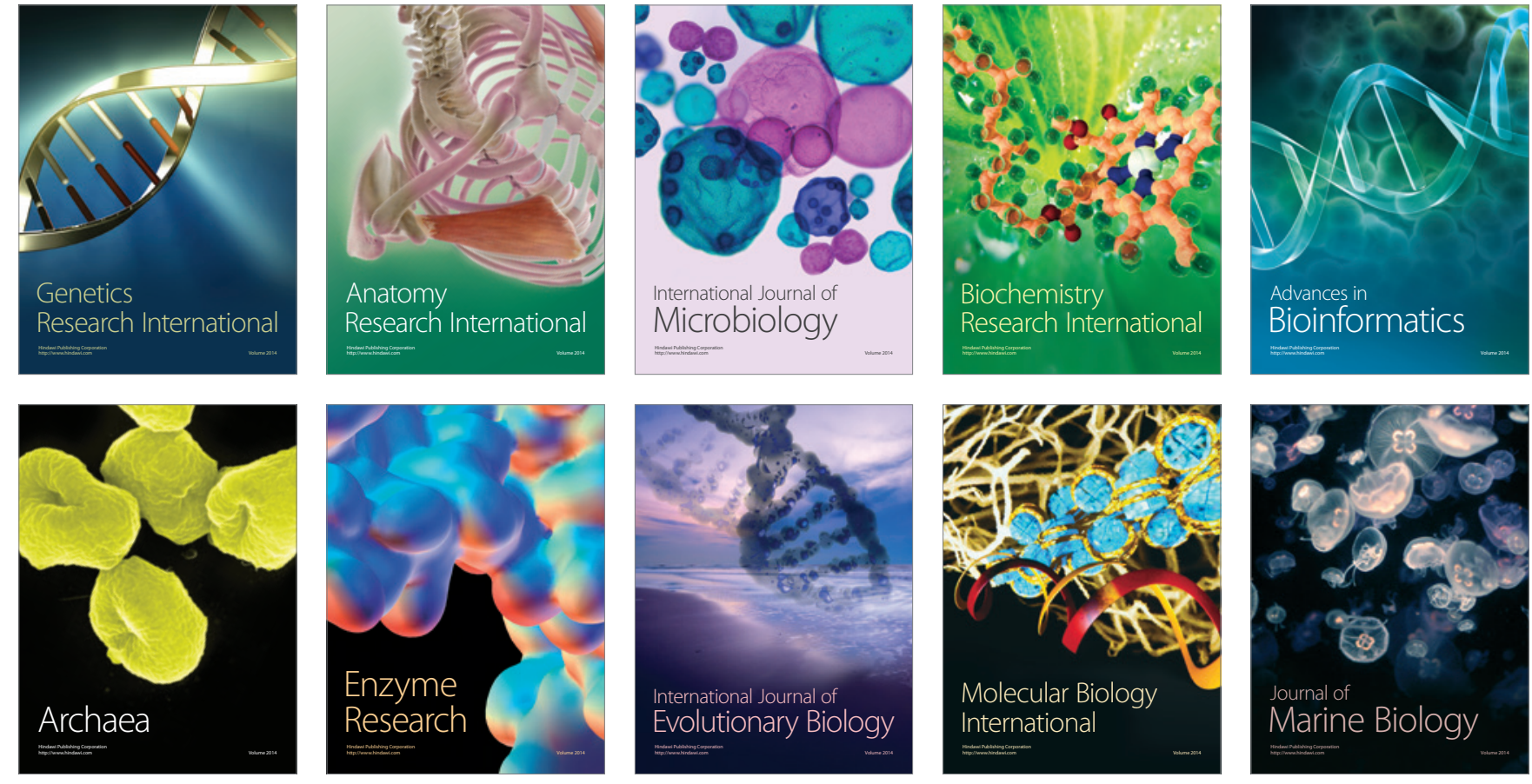